INSTITUT NATIONAL DE LA STATISTIQUE ET DES ETUDES ECONOMIQUES

Série des Documents de Travail du CREST

(Centre de Recherche en Economie et Statistique)

\author{
$\mathrm{n}^{\circ}$ 2010-45 \\ Do Unemployed Workers Benefit \\ from Enterprise Zones? \\ The French Experience \\ L. GOBILLON $^{1}-$ T. MAGNAC ${ }^{2}$ \\ H. SELOD ${ }^{3}$
}

Les documents de travail ne reflètent pas la position de I'INSEE et n'engagent que leurs auteurs.

Working papers do not reflect the position of INSEE but only the views of the authors.

\footnotetext{
1 Institut National d'Etudes Démographiques, PSE and CREST.

2 Toulouse School of Economics, Université de Toulouse (GREMAQ \& IDEI).

3 The World Bank, Paris School of Economics and CREST.
} 


\title{
Do unemployed workers benefit from enterprise zones? The French experience
}

\author{
L. Gobillon* T. Magnac $\dagger$ H. Selod ${ }^{\ddagger}$ \\ First version, December 2008 \\ This version: October 25, 2010
}

\begin{abstract}
This paper is a statistical evaluation of the 1997 enterprise zone program in France. We investigate whether the program increased the pace at which unemployed workers residing in targeted municipalities and surrounding areas find employment. The work relies on a twostage analysis of unemployment spells drawn from an exhaustive dataset over the 1993-2003 period in the Paris region. We first estimate a duration model stratified by municipalities in order to recover semester-specific municipality effects net of individual observed heterogeneity. These effects are estimated both before and after the implementation of the program, allowing us to construct variants of difference-in-difference estimators of the impact of the program at the municipality level. Following extensive robustness checks, we conclude that enterprise zones have a very small but significant effect on the rate at which unemployed workers find a job. The effect remains localized and is shown to be significant only in the short run.
\end{abstract}

*Institut National d'Etudes Démographiques, PSE and CREST. Address: INED, 133 boulevard Davout, 92245 Paris Cedex, France. E-mail: laurent.gobillon@ined.fr.

†Toulouse School of Economics, Université de Toulouse (GREMAQ \& IDEI) Address: Manufacture des Tabacs, 21 allée de Brienne, 31000 Toulouse, France. E-mail: magnac@cict.fr.

†The World Bank, Paris School of Economics and CREST. Address: The World Bank, Development Economics Research Group, 1818 H Streeet, NW, Washington, DC 20433, USA. E-mail: hselod@worldbank.org. 


\section{Introduction ${ }^{1}$}

Most cities have distressed neighborhoods where jobs are few and unemployment is rampant. As a response, considering that the lack of labor demand in poor areas is a key contributor to unemployment, a number of countries -including the US, the UK and France- have implemented spatially targeted policies to encourage job creation or job relocation to these areas. Such policies -often labelled enterprise zone programs (EZ hereafter)- revolve around the simple idea that granting fiscal incentives to firms located in distressed neighborhoods would boost local hires. Although intuitively appealing, enterprise zones are controversial as many observers have questioned their ability to reach their objectives and whether achieved benefits are sufficient to balance costs (Peters and Fishers, 2004).

The goal of the present paper is to provide an econometric evaluation of the French experience in this domain, focusing on the Paris region for which there exists a dataset that allows an adequate evaluation of the policy at the municipality level. The key measure in the French program is that, in order to be exempted from the wage tax, firms needed to hire at least $20 \%$ of their labor force locally (after the third hired worker). In the French context, this is a significant incentive as the wage tax exemption is larger than a third of all labor costs borne by employers depending on the wage level and type of worker. The policy was expected to improve local employment through hires made by existing, relocating, or newly-created firms that would draw from the local pool of unemployed workers.

Our approach for the impact evaluation of the program is original in various ways.

\footnotetext{
${ }^{1}$ The authors are grateful to participants at the following conferences and seminars: NARSC '08, EALE '09, ESEM '09, and London School of Economics, for their helpful comments, and particularly to Shawn Rohlin, Jeffrey Zax and Roland Rathelot. They would also like to thank the French Ministry of Health (MiRe-DREES) and the French Ministry of Labor (DARES) for financial support. The opinions expressed in this article are those of the authors and do not necessarily reflect the views of our employers, including the World Bank, its Executive Board, or the countries represented. All remaining errors are ours.
} 
First, we depart from the approach used in previous papers in the literature as we investigate the propensity of local unemployed workers to find a job. In the past, evaluations of enterprise zones usually focused on the growth in the local number of establishments or on the number of local jobs that were created as a result of the policy. Nonetheless, using job creation as a measure of policy outcome misses part of the story as it is usually impossible to tell whether job creations benefit local residents or residents from non-targeted areas. Instead, in the present paper, we investigate how the policy affects the flow out of unemployment, distinguishing between locations. This is a more appropriate indicator of policy success given the explicit policy goal of helping unemployed workers residing in distressed areas find jobs.

Second, focusing on unemployment duration has the advantage of capturing the overall local effect of job creations on the propensity to find a job. Indeed, policy evaluations that focus exclusively on job creations in new establishments are likely to provide a biased estimate of the effect by overlooking the fact that jobs may also be created in existing firms or that there could be some substitution of jobs between existing firms and new establishments. Focusing on unemployment duration eliminates these problems.

Third, we propose a new econometric methodology that allows for a fine estimation of the policy's local effects while controlling for the composition of the sample in each location, thus avoiding composition bias in the estimation. We use a two-stage procedure, which revolves around the estimation of a proportional hazard model of individual unemployment durations which is stratified by municipality and which controls for individual characteristics. In the first stage, we use the Stratified Partial Likelihood Estimator (SPLE) proposed by Ridder and Tunali (1999) and compute spatial effects for each of the 1,300 municipalities that form the Paris region. These municipality effects are purged of the effects of individual observed characteristics for each semester between 1993 and 2003 and capture all municipality characteristics that have an impact on unemployment duration. Right censoring that affects unemployment durations is also controlled for. In a second 
stage, in order to assess the effect of the policy, we measure how these municipality effects changed over time (before and after the creation of enterprise zones) comparing municipalities that host an enterprise zone -the "treated" municipalities- and other municipalities of comparable characteristics. This second stage uses matching and differences in differences techniques to address possible issues of treatment selectivity.

Fourth, we use a large number of localities (i.e. 1,300) for the stratification in the estimation of the unemployment duration model. A municipality corresponds to the finest spatial unit of analysis that is available in the data. Since municipalities have a population size which is broadly twice that of the enterprise zone they contain, this means that we capture net effects in the EZ and non-EZ parts of a same municipality only. Since municipalities are relatively small, however, we are able to investigate the possibility of spatial spillovers on neighboring municipalities.

Finally, our work complements the only existing econometric study of enterprise zone programs in France, which found only a limited impact on the growth in the number of establishments (see Rathelot and Sillard, 2009).

Our core approach to estimate the effect of the policy contrasts exit rates from unemployment between municipalities which are selected for the policy and municipalities in a comparison group around the date of implementation of the policy. Several methods were at our disposal in the toolkit of evaluation methods (see Blundell and Costa-Dias, 2009, for a recent survey). Because the sample we are considering is small, we resort to a linear model rather using non-parametric methods. Second, in the absence of a controlled experiment, the key was the construction of the comparison, or control group, in a very careful way (Smith and Todd, 2005). In the French experience, zone designation was based on a criterion that included measures of population and labor force composition. Political tampering implied that the municipalities that were not targeted by the program but have characteristics similar to those of treated municipalities can be used as a control group. To match municipalities, we started by estimating the propensity score - i.e. the 
probability of being chosen as an enterprise zone municipality - as a function of the same variables that were officially used to construct an eligibility criterion in the French enterprise zone program. Based on this propensity score, we then constructed a control group of municipalities whose propensity score is in the same range as that of treated municipalities, ensuring that municipalities in both groups share the same conditions. However, the data clearly tell that the set of variables included in the eligibility criterion is not rich enough to account for the heterogeneity in outcomes between treated and control municipalities (Smith and Todd, 2005). Conditioning on municipality geographic conditions was thus also necessary. This is why we ended up using a difference in differences approach combined with matching on a propensity score (Heckman, Ichimura and Todd, 1997). The results of our empirical strategy prove to be robust to a variety of appropriate robustness checks relative to redefinitions of treatment and control so as to capture spillover effects, to various weighting schemes or to the introduction of other controlling factors.

Our results point to three important conclusions for public policy. First, we find evidence that the policy tended to "pick winners", that is to select municipalities in which unemployed workers face better prospects, a common feature in many EZ programs. More importantly, we find that enterprise zones have a moderate (3\%) but significant impact on unemployment exit rates to employment in the short run (at most 3 years). We do not find evidence of medium run effects (between 3 and 6 years) although this could potentially be attributed to the failure of the common trend assumption underlying difference-in-difference estimation. Finally, the effect on unemployment exits remains localized and no spillover effects are significant.

The structure of the paper is as follows. Following this introduction, we provide a survey of the literature on enterprise zones in a second section. We present the French enterprise zone program in a third section. We then describe our data in a fourth section. A fifth section explains our estimation strategy, while a sixth section discusses the results of the policy evaluation. A seventh section concludes and offers a policy discussion. 


\section{Enterprise zones: a survey of the literature}

Enterprise zones (EZ) programs are territorial discrimination policies that consist in providing tax incentives and exemptions from regulations to specific blighted areas. The objective is to promote local economic development and, in particular, to improve the level of local employment through incentives for firms to invest, hire, locate or relocate to the targeted areas. The concept, which was initially inspired by the rapid development of free trade zones in the early 1970s in emerging economies, was first used as a tool for urban policy by the United Kingdom in 1981. In the wake of the UK initiative, several US states also enacted similar legislations, starting with Connecticut. Furthermore, a US federal program of empowerment zones was implemented in several cities in 1994. It provided not only tax incentives to the firms but also important social service block grants-i.e. lump sum transfers from the federal government to States that are spent on targeted areas. Following these experiences, France voted its first EZ program in 1996.

A comparison of existing EZ programs shows that the specific fiscal tools that are used vary widely from different forms of relief on capital taxation to employment and hiring tax credits, or a combination of both. The specific tools may also vary depending on the zone designation process, the conditionality for tax credit eligibility, the intensity and scope of the tax credits, the duration and phasing out of the exemptions, the time frame of the program, the spatial coverage and the number of zones, the requirement to simultaneously implement a local urban development plan, or whether foregone local tax revenues are partially or completely compensated by the State.

In theory, enterprise zone programs are expected to contribute to local economic development through several mechanisms depending on the specific features of the program and the context. In what follows, we will focus on whether they can succeed in promoting employment. The effect of capital subsidies is ambiguous. Although capital subsidies (like e.g. credit on local property tax,

or tax credit on inventories) should encourage investments, this could happen at the expense of employment if capital and labor are substitutes in production (Lynch and Zax, 2008). In the case 
of factor complementarity, however, capital subsidies could be expected to have a positive effect also on employment. As for labor subsidies (like e.g. relief on wage taxes), they should have an unambiguous effect on employment by strengthening the incentives to hire workers. Income tax rebates should encourage both hiring and investments.

Despite the mechanisms just described, several criticisms grounded in economic theory have been formulated. A first issue is that fiscal incentives may only turn out to provide windfall effects to firms who would have hired workers in any case, with little impact on the local level of employment. But then, conditioning the tax credits on local hiring - as it is often the case in enterprise zone programs - should address this problem and improve employment, at least in targeted areas. Another related issue is that enterprise zones may not necessarily result in job creation but could cause geographical shifts in jobs from non-EZ to EZ areas. However, even if it turns out to be the case, it is not clear whether this should be considered a failure of the policy as it can be socially desirable to spatially redistribute jobs to places of low employment, even in the case of a zero-sum game. A third argument is that zone designation may result in the stigmatisation of the targeted neighborhood, further exacerbating the redlining behavior of employers. The issue is then whether the adverse indirect effect of stigmatisation outweighs the expected direct beneficial impact on employment. A fourth objection stresses that in the absence of tax revenue compensation, enterprise zone programs may lead to a decrease in the local provision of public services, which in turn could have a detrimental effect on employment - and in any case on the welfare of the local population. Of course, this depends on the way the EZ program and infrastructures are funded. The problem can be addressed by ensuring that the enterprise zone legislation provides appropriate mechanisms for compensation or can be avoided altogether if the burden of the tax cuts is directly borne by the State and not by the local government. Moreover, a fifth criticism argues that the effects of enterprise zones could be only transitory and will cease with the phasing out of the exemptions. As a matter of fact, in many cases, exemptions 
have been extended passed the initial deadline - although this may involve the perpetuation of a costly policy. Lastly, it can be argued that providing only fiscal incentives could be insufficient to improve local employment when unemployment is structural as is the case for instance when there is a mismatch between unemployed workers' skills and job requirements. This argues in favor of integrated policies beyond the sole stimulation of labor demand.

In view of these arguments, whether enterprise zones successfully manage to improve employment may strongly depend on the specificity of each program and on the local context. This clearly makes the evaluation of EZ programs a key empirical matter for policy makers and explains the relatively abundant literature on the topic (see Ladd, 1994, Peters and Fisher, 2004, and Hirasuna and Michael, 2005, for surveys). It is only in the mid 1990s however that proper evaluations started to emerge, resorting to a variety of statistical techniques and focusing on a variety of labormarket indicators. ${ }^{2}$ The main usual challenge in such evaluations is to address selection issues. Areas are often selected according to a ranking using some economic indicator as well as on possible political tampering from local government representatives seeking benefit from the policy for their constituencies. Addressing this issue thus requires resorting to quasi-experimental techniques using panel data to control for local heterogeneity. Identification strategies typically range from random growth models to difference in differences, possibly using propensity score matching to define adequate control groups or propensity score reweighting to construct some counterfactuals. In the US, the econometric evaluations of state EZ programs reported in the economic literature provide mixed results. To our knowledge, the first such study is Papke (1994) who evaluates the effect of the 1983 Indiana enterprise zone program, which consisted in providing credits to firms on the local property and inventory tax - as well as in granting residents an income tax deduction - in a selection of areas in central cities. The author's main finding is that annual local unemployment

\footnotetext{
${ }^{2}$ Many past evaluations undertaken before the mid 1990s, did not apply the now-standard techniques of public policy evaluation. In some cases, evaluations were not carried out by parties external to the program. This resulted in a controversial literature with sometimes unclear and contradictory results.
} 
claims declined by a surprisingly high $19 \%$ following zone designation. Given the modesty of employment incentives in the program, the author suggests that this result may reflect some "demonstration effect" as was indeed described by zone administrators. Elvery (2009) studies the EZ programs in California and Florida and finds no evidence that enterprise zones have affected the individual probability of employment for zone residents. Focusing on the 1984 New Jersey program, Boarnet and Bogart (1996) look at the number of job creations in municipalities with an enterprise zone. As they do not find any effect, they speculate that this could be due to a shift in jobs from non-EZ to EZ areas within the concerned municipalities.

These contrasting results raise the issue that some enterprise zone policies may be more successful than others. This is tested by Bondonio and Engberg (2000) who assess the effect of enterprise zone programs in five different states $^{3}$ on local employment at the ZIP-code level while also controlling for the monetary value of the incentives. They find very little impact on the difference between nonEZ and EZ employment growth. Like Boarnet and Bogart, they suspect that this weak aggregate effect could be due to job transfers from non-EZ to EZ areas within the same ZIP-code area and from old to new firms within the same ZIP-code area. The latter argument is consistent with the idea that start-ups could drive away existing businesses during the implementation of the program.

To further estimate the dynamics at work beyond the average impact estimated in previous studies, Bondonio and Greenbaum (2007) focus on the effects of enterprise zone programs in ten states ${ }^{4}$ and Washington, DC. Their approach consists in separately evaluating the effects of the EZ program on new, existing and vanishing establishments. Consistently with Bondonio and Engberg (2000)'s intuition, they find that enterprise zone programs increase employment in new establishments but that this is offset by the accelerated loss of employment in vanishing establishments. They

\footnotetext{
${ }^{3}$ California, Kentucky, New York, Pennsylvania and Virginia.

${ }^{4}$ California, Connecticut, Florida, Indiana, Kentucky, Maryland, New Jersey, New York, Pennsylvania, and Virginia.
} 
are also able to identify which features of the programs have greater positive impacts on existing businesses, stressing the role of incentives tied to job creation and of strategic local development plans.

O'Keefe (2004) investigates two other issues concerning enterprise zone programs: whether possible effects on employment are transitory or permanent, and whether wage tax credits are captured by higher wages. Using annual establishment-level employment data at the census tract level between 1992 and 1999 in California - where the enterprise zone program provides hiring credit for low wages to be phased out after six years - she finds that employment in targeted zones grew 3.1 percent faster the first six years after designation than it would have in the absence of the program. But the effect is only transitory. She suggests that the waning of the effect could be explained by the phasing out of the hiring incentive, and also by the reduced availability of vacant properties for businesses and firms in the zone as the years pass. As for wages, they do not seem to be affected by the enterprise zone program. Nonetheless, these findings on the California program have been challenged by other studies. The results on employment are contradicted by Neumark and Kolko (2010) who use the precise street boundaries of enterprise zones and check whether establishments are located within these boundaries over the 1992-2004 period. They find that the effect of enterprise zones on employment is insignificant both in the short and the long run. O'Keefe's results on wages are also contradicted by Bostic and Prohofsky (2006) who show, using administrative fiscal data, that the income of enterprise zone participants in California increased more rapidly than for controls.

Since 1994, a federal "empowerment zone" program has complemented the enterprise zone policies that were initiated by states. This program created empowerment zones in six urban communities $^{5}$ where local firms were granted substantial tax credits for each employee living and working in the concerned areas. Empowerment zones also became eligible for important block grant

\footnotetext{
${ }^{5}$ Atlanta, Baltimore, Chicago, Detroit, New York City, and Philadelphia/Camden.
} 
funds from the federal government which could be used for social purposes. Other policy measures included grants meant to facilitate large-scale physical development projects, tax-exempt bonds to businesses, and write-offs from taxes (see Busso and Kline, 2008 for more details). Evaluations of the effects of the federal program on labour market performances are reported in several studies. In particular, Busso and Kline (2008) compare census tracts in designated zones with tracts including rejected zones or which ended up designated only at a later date. They find that EZ programs had a positive effect on local employment and a negative effect on the local poverty rate. Their results on employment and poverty are debated by Hanson (2009) who argues that EZ designation might have been endogenous. When instrumenting EZ designation by political variables, he finds that EZ programs had no effect on employment and poverty.

\section{$3 \quad$ Enterprise zones in France}

France launched its first enterprise zone program on January 1, 1997 by creating 44 enterprise zones (Zones Franches Urbaines in French), among which 38 are located in metropolitan France, and 9 in the Paris region. ${ }^{6}$ Enterprise zones are the smallest level of a nested three-tier zoning system of distressed areas around which France organizes its urban policy interventions. While the first and second tier (the Zones Urbaines Sensibles and Zones de Redynamisation Urbaine respectively) are mostly the focus of social programs and urban revitalization projects, the third tier — which groups areas that are most distressed — was only defined for the specific implementation of the French EZ program (see Observatoire National des Zones Urbaines Sensibles, 2004, for more details). Since

\footnotetext{
${ }^{6}$ The 9 targeted neighborhoods in the Paris region are located within or across 13 municipalities. The list is as follows: Beauval / La Pierre Collinet (in the municipality of Meaux), Zup de Surville (in Montereau-Fault-Yonne), Le Val Fourré (in Mantes-la-Jolie), Cinq Quartiers (in Les Mureaux), La Grande Borne (in Grigny and ViryChâtillon), Quartier Nord (in Bondy), Grand Ensemble (in Clichy-sous-Bois and Montfermeil), Le Bois L'Abbé / Les Mordacs (in Champigny-sur-Marne and Chennevières-sur-Marne), Dame Blanche Nord-Ouest / La Muette / Les Doucettes (in Garges-lès-Gonesse and Sarcelles).
} 
the number and intensity of fiscal exemptions is gradually increased when comparing the first, the second, and the third tiers of urban interventions, EZs benefit from the complete set of fiscal incentives.

As is well known in France, the selection of enterprise zones was clearly not random. Municipalities or groups of municipalities had to apply to the program and projects were selected according to their ranking given by a synthetic indicator. This indicator aggregates 5 criteria based on the population of the zone, its unemployment rate, the proportion of youngsters, the proportion of workers with no skill, and the so-called "fiscal potential" of the municipality or municipalities in which the zone is located. ${ }^{7}$ Nevertheless, the views of local and centralized government representatives who intervened in the geographic delimitation of the zones were also taken into account. After application of the criteria and consideration of local interests, enterprise zones ended up being large neighborhoods of at least 10,000 inhabitants that had particularly severe unemployment problems.

Figures from the 1999 Census of the Population (the closest year to the designation date) indicate that 730,000 people, around $1.25 \%$ of the French population at that time, resided in these zones. The nine enterprise zones in the Paris region hosted almost 220,000 inhabitants, i.e. $2 \%$ of the population of the region. They also accounted for a significant portion of the population in the municipalities where they are located (between 22 and $68 \%$, and $45 \%$ on average).

The fiscal incentives were uniform across the country and consisted in a series of tax reliefs on property holding, corporate income, and in particular wages (see DARES, 2004, for more details). ${ }^{8}$

\footnotetext{
${ }^{7}$ The "fiscal potential" is the fictive local amount of taxes that would be collected if tax rates were uniform across all municipalities in France. The formula for the synthetic indicator is the product of the first four criteria divided by the fifth (see DIV, Observatoire National des Zones Urbaines Sensibles, 2004).

${ }^{8}$ Exemptions concern the specific following taxes: charges sociales patronales (employers' social security contribution which constitutes the "wage tax"), taxe professionnelle (business rate), impôt sur les bénéfices (profit tax), taxe foncière (property tax), and cotisations sociales personnelles maladie et maternité (individual health insurance contributions).
} 
The key measure was that firms needed to hire at least $20 \%$ of their labor force locally (after the third worker hired) in order to be exempted from the wage tax (mainly employers' contribution to national insurance). These exemptions were meant to be temporary and were more advantageous for small firms (i.e. establishments with less than 5 salaried workers) which benefited from a 9-year rather than a 5-year exemption completed by a 3 year degressive exemption. The program was meant to last until January 1, 2002, but exemptions were extended beyond that date. At that time, they were also slightly modified and the local employment threshold was increased to $33 \%$. In 2004, 41 new enterprise zones were created. In 2006, an additional 15 were added to the list.

Surprisingly, no evaluation of the French enterprise zone program was initially planned. Although some "evaluations" based on descriptive statistics were subsequently carried out by different public authorities, they yielded opposite conclusions from "no effect" to "considerable effects" (DIV, 2001, André, 2002). Whereas descriptive statistics suggested that enterprise zones affected the local dynamics of job and establishment creations, they depicted a potentially ambiguous effect on unemployment. Between 1997 and 2001, the ratio of establishment openings to the initial stock of establishments has been estimated at $236 \%$ in enterprise zones, compared to $76 \%$ in the rest of the metropolitan areas where EZs are located (Ernst, 2008). Note however that these figures are gross establishment creations and do not take into account destructions. Interestingly, the 5-year survival rates of establishments are quite similar in EZs and the rest of their metropolitan areas.

The increase in the number of establishments, however, may not fully percolate to an increase in local employment because firms in enterprise zones are typically very small. It has been calculated for instance that $50 \%$ of hired workers in EZ's in 2002 were hired by firms of less than 10 salaried workers, and that $15 \%$ of the firms in EZs had no salaried worker at all (Thélot, 2004). Although not a statistical evaluation of the EZ program, Gilli (2006) reports that between 1997 and 2002, the number of jobs in the 38 metropolitan enterprise zones grew from 27,000 to 72,000. Even though the increase seems large in relative terms, it is less drastic when compared to the resident 
population. In fact, jobs remained scarce with respect to the size of the labor force. While there were approximately 10 jobs for 100 labor force participants in EZs in 1997, the figure only increased to 13 jobs for 100 labor force participants in 2003. Although an improvement, this remains rather small. In addition, $22 \%$ of job creations in EZs are believed to have resulted from the relocations of firm which may have brought some workers with them.

Although these figures are interesting per se, they do not constitute an assessment of the effects of the French enterprise zone program. To our knowledge, the only existing econometric evaluation of enterprise zones is Rathelot and Sillard (2009) who focus on the effect of enterprise zones on establishment creation and salaried employment. Their identification strategy takes advantage of the transformation of a number of community redevelopment areas (Zones de Redynamisation Urbaines) into enterprise zones (Zones Franches Urbaines) in 2004 when the second wave of enterprise zones was enacted. Using difference in differences techniques, they find that enterprise zones had only a modest effect on establishment creation and salaried jobs (possibly 4,000 jobs between 2004 and 2006 for the whole country).

Our study departs from Rathelot and Sillard (2009) in two important respects. First, we focus on the creation of the first wave of enterprise zones in 1997. This enables us to measure the whole effect of the enterprise zone creation rather than just an incremental effect of the territorial policy (an intensification of the incentives provided to employers with the passage of the second to the third tier of urban interventions). Secondly, we focus on the effect of the policy on local unemployment rather than on local jobs (which may partly benefit non-residents). To this end, we use individual data on unemployment rather than firm data on employment.

\section{The Data}

We focus on the Paris region, which roughly corresponds to the Paris metropolitan area. With 10.9 million inhabitants, the region is subdivided into 1,300 municipalities including the 20 subdistricts 
of the city of Paris. These municipalities have very different population sizes that range from 225,000 residents in the most populous Parisian subdistrict to small villages located some $80 \mathrm{~km}$ away from the city center (Source: 1999 Census of the Population).

We use the historical file of job applicants to the National Agency for Employment (Agence Nationale pour l'Emploi or ANPE hereafter) for the Paris region. The sample includes all unemployment spells ending in the period running from July 1993 to June 2003. This interval includes the implementation date of the enterprise zone program (January 1, 1997) and is broad enough to study the effect of enterprise zones not only in the short run, but also in the medium run. It is an almost exhaustive dataset of unemployment spells in the region given that registration with the national employment agency is a prerequisite for unemployed workers to be able to claim unemployment benefits in France. It contains information on the exact date of an application (the very day), the unemployment duration in days, the reason for which the application came to an end, the municipality where the individual resides, and a set of socio-economic characteristics reported upon registration with the employment agency (age, gender, nationality, diploma, marital status, number of children and disabilities).

We decided to focus on unemployment spells that began at most four years before July 1, 1993 (i.e. after July 1, 1989) and artificially censored the few spells which lasted longer than four years. This is because the assumptions underlying our duration model are unlikely to be satisfied for very long spells. After eliminating the very few observations for which some socio-economic characteristics are missing, we are able to reconstruct 8,831,456 unemployment spells ending in the period between July 1, 1993 and June 30, 2003. These unemployment spells may end when the unemployed find a job, drop out of the labor force, leave unemployment for an unknown reason or when the spell is right censored. Given the focus of the paper, we will mainly study exits that end with finding a job, all other exits being treated as right-censoring in the analysis.

We first graphically describe the evolution of the variables of interest over the period of ob- 
servation. We report in Figure 1 the unemployment rate in the region (from the Labour Force Surveys) as well as the exit rate (to any destination) and the entry rate, both computed from our data. ${ }^{9}$ As justified later on, the time frequency that we use is the semester, with semester 1 corresponding to the second semester of 1993.

\section{[Insert Figure 1]}

In the period running from the second semester of 1996 (semester 7) to the first semester of 1999 (semester 12), there is no common trend for unemployment and exit rates since the unemployment rate is rather flat while the exit rate is decreasing. Interestingly, the entry rate into unemployment follows the same decreasing pattern. Stable unemployment in this period is thus concealing decreasing entry and exit rates. The period from the second semester of 1999 (semester 13) until the first semester of 2001 (semester 16) exhibits a different pattern. Unemployment decreases whereas both entry and exit rates increase. After the second semester of 2001 (semester 17), the exit rate falls below the entry rate and unemployment increases.

To complete this description, Figure 2 reports the evolution of the different rates of exit from unemployment by destination type, i.e. to a job, to non-employment or for unknown reasons. The exit rate to non-employment is relatively constant. The exit rate to a job trends downwards around the time the policy is implemented in the first semester of 1997 (semester 8). Note also that the rate of exits for unknown reasons slightly increases after the second semester of 1999 (semester 13). It suggests that some rules may have changed at that time in the way exits are recorded and

\footnotetext{
${ }^{9}$ The entry rate is the number of new unemployed workers within the semester divided by the number of unemployed workers at risk at the beginning of the semester. Since there are strong seasonal elements regarding the entry rate, we graphed a moving average of order 2 so as to smooth the curve and make the graph more readable. The exit rate to a given destination is the number of unemployed workers experiencing a transition to this destination within the semester divided by the number of unemployed workers at risk at the beginning of the semester.
} 
in the empirical analysis below we will assess whether this change affects the evaluation.

$$
\text { [Insert Figure 2] }
$$

Secondly, descriptive statistics on the number of unemployed workers at risk and the number of exits to a job are reported by semester in Table 1 for the whole region (first two columns). The number of unemployed workers at risk is nearly constant from 1993 to 1999 and then decreases before increasing again in 2001. This is consistent with a sharp decrease in the unemployment rate after 1999 as was seen in the above graphs. The number of exits to a job does not follow exactly the same pattern as the decrease occurs sooner, in 1996, as seen in Figure 2.

\section{[Insert Table 1]}

Over the whole period, the proportion of exits to a job decreases from $11.2 \%$ to $7.2 \%$.

We also reported in Table 1 the same statistics for municipalities which size is in the 8,000100,000 range as we will restrict our working sample to that range in the policy evaluation section. This range contains all treated municipalities and comprises approximately 300 municipalities out of the 1,300 in the Paris region. There are no noticeable differences between this restricted sample and the full sample. Roughly speaking an average of 90,000 persons find a job each semester and this corresponds to about 300 exits per semester in each municipality. These figures explain why we chose semesters as the time intervals in our analysis since using shorter periods would imply too much variability due to the small sample size.

The raw data used in the evaluation of the EZ program are described by Figures 3 to 6 . Figure 3 reports the evolution of the exit rates in the sample of treated municipalities and in three control groups: a sample composed by non-treated municipalities between 8,000 and 100,000, and two subsamples of that group made of municipalities located at a distance between 0 and 5 kilometers of an EZ, or between 5 and 10 kilometers. For readability, we drew a vertical line at semester 8 (first semester of 1997) when the policy started to be implemented. The curves for the control 
groups are broadly decreasing and exhibit parallel trends throughout the period. The curve for the treatment group slightly diverges from the trends observed for the control municipalities between semesters 1 and 12 (second semester of 1993 to first semester of 1999). In particular, the exit rate to a job remains flat in the treatment group between semesters 7 and 8 (second semester of 1996 and first semester of 1997) when the policy enters into effect whereas it is decreasing in the control groups. The estimation of the treatment parameter that we undertake in the remaining sections of the paper is a way of formalizing and testing that these diverging trends are statistically significant.

None of these differences seems to appear in graphs reporting the evolution of exit rates to nonemployment (Figure 4) and the evolution of exit rates for unknown reasons (Figure 5). In the latter Figure, it is noticeable that exit rates for unknown reasons become larger in treated municipalities the semester after the implementation of the treatment. However, our treatment parameter using information on reported exits to a job would be underestimated only if a substantial fraction of exits to a job are concealed among exits for unknown reasons. We attempt to estimate this effect later on and find that the apparent increase is spurious (see Table 15). In Figure 5, it is also noticeable that censorship due to exit rates for unknown reasons increased between semesters 12 and 14 (first semester of 1999 and first semester of 2000), which is consistent with our previous remarks on Figure 2.

Lastly, Figure 6 represents the evolution of exit rates to a job, distinguishing between two groups of municipalities depending on the share of their population residing in the enterprise zone. The "flattening" effect between semester 7 (before treatment) and semester 8 (after treatment), as already seen in Figure 3, is much more pronounced in municipalities in which the enterprise zone host a larger fraction of the population. As a matter of fact, rates of exit to a job even increased in those municipalities.

Turning to the composition of the sample before and after the beginning of policy implemen- 
tation, we report in Tables 2 and 3 some descriptive statistics at two dates before and after the creation of enterprise zones (we chose the first semester of 1994 and the first semester of 2000, which defines a period over which the exit rates are decreasing). These Tables show that the sample averages are close at the two dates. There are some slight differences in gender composition though as the proportion of females in the sample increases from $49.1 \%$ in 2000 to $52.2 \%$ in 1994. Interestingly, there are also relatively more foreigners in the sample of unemployed workers in $2000(26.9 \%)$ than in $1994(22.5 \%)$. This pattern concerns all classes of foreign nationalities except Europeans (other than French), i.e. North Africans, Sub-saharan Africans, and other nationalities. We attribute these effects to dynamic selection biases at the entry into and the exit out of unemployment. The population at risk is increasingly made of subpopulations that have a higher entry rate and a lower exit rate since exit rates to a job trended downwards between these two periods. All in all, the average unemployment duration before finding a job increases from 235 days to 274 days.

\section{[Insert Tables 2 and 3]}

\section{The econometric strategy}

In theory, all unemployed workers can be affected by the enterprise zone program although individuals are more likely to be affected if they reside in an enterprise zone - because of the requirement about local employment - or if they live close to an enterprise zone because of spillover effects which can play in both directions (see our short survey of the literature above). Given that enterprise zones are clusters of a significant size within or across municipalities, it would be desirable to try and detect the effect of the policy - if any — at the level of an enterprise zone. Nevertheless, our data does not allow us to work at this fine level of disaggregation and our approach retains municipalities as our spatial unit of analysis. Municipalities have on average twice the population 
of the EZ they contain. Any aggregate effect at the municipality level will measure the effect of local job creation net of within-municipality transfers.

Our raw data consists of individual unemployment spells observed over time. In order to measure the effect of the EZ program, we start in a first stage by estimating semester-specific municipality effects on the propensity to find a job while netting out the effects of observed individual characteristics (gender, age, nationality, diploma, family structure, disability) and the economic conditions. These municipality effects measure the chances of finding a job for unemployed workers in each municipality during each semester, all things else being equal. In a second stage, we then resort to various difference in differences approaches and compare the evolution of these municipality effects before and after the implementation of the policy between treated municipalities and various control groups of other municipalities.

In a first subsection, we explain how the coefficients of individual variables used as controls are estimated. In a second subsection, we explain how to recover the semester-specific municipality effects. Finally, in a third subsection, we turn to the estimation of our parameter of interest: the effect of enterprise zone designation on the exit rate from unemployment to a job at the municipality level.

\subsection{Estimating the effects of individual variables}

Consider an individual $i$ who enters unemployment at a given entry date $t_{0 i}$, which is the realization of a random variable denoted $T_{0 i}$. The unemployment spell of that individual ends when a job is found or when it is right-censored. Right-censoring groups all other exit types: end of the panel, dropping out of the labor force or disappearance from the records for an unknown cause.

Denote $T_{i}$ the latent date at which the individual finds a job and $t_{i}$ its realization. The corresponding latent duration is $D_{i}=T_{i}-T_{0 i}$, with realization $d_{i}$. Also denote $T_{c i}$ the latent date of right-censoring and $D_{c i}=T_{c i}-T_{0 i}$ the duration until right-censoring. The observed duration of 
the unemployment spell is then $\min \left(D_{i}, D_{c i}\right)$. We assume that the latent duration until finding a job and the latent duration ending with right censoring are independent.

For an individual $i$, we denote $\lambda\left(d \mid \widetilde{X}_{i}, j(i), t_{0 i}\right)$ the hazard rate for exiting to a job at duration $d$ where $\widetilde{X}_{i}$ is a set of non-time varying individual explanatory variables, and $j(i)$ is the municipality in which the individual resides. Note that the hazard rate is written as a function of the entry date $t_{0 i}$ for the sake of flexibility.

With these definitions in mind, we can now consider a duration model where observations are clustered by municipality and semester. The time interval between July 1, 1993 and June 30, 2003 is split into $S$ semesters denoted $\left[\tau_{q}, \tau_{q+1}\right)$. For $q=1, \ldots, 20$. From now on, we will refer to semester $q$ to designate $\left[\tau_{q}, \tau_{q+1}\right)$. Denote $s=\sum_{q=1}^{20} q .1\left\{\tau_{q} \leq t_{0 i}+d<\tau_{q+1}\right\}$ the semester during which the unemployed worker $i$ exits after an unemployment spell of duration $d$ (ie. $t_{0 i}+d \in\left[\tau_{s}, \tau_{s+1}\right)$ ). The hazard rate function is specified as proportional:

$$
\lambda\left(d \mid \widetilde{X}_{i}, j(i), t_{0 i}\right)=\theta^{j(i)}(d, s) \exp \left(X_{i} \beta_{s}\right)
$$

where $\theta^{j}(d, s)$ is the baseline hazard rate in municipality $j$ during semester $s$, and $X_{i}=\left[\widetilde{X}_{i}, A_{i}\right]$ where $A_{i}$ are indicators of months and years of entry calculated from $t_{0 i}$. The vector of parameters $\beta_{s}=\left[\beta_{s}^{\tilde{X}^{\prime}}, \beta_{s}^{A \prime}\right]^{\prime}$ can be decomposed into parameters corresponding to the individual variables $\widetilde{X}_{i}\left(\operatorname{denoted} \beta_{s}^{\widetilde{X}}\right.$ ) and parameters corresponding to the indicators of months and years of entry $\left(\right.$ denoted $\beta_{s}^{A}$ ). The hazard rate is assumed to depend on both semesters and municipalities to take into account the possibility that local policies and local economic conditions may vary over time.

We follow Gobillon, Magnac and Selod (2010) who extend the set-up proposed by Ridder and Tunali (1999) of Stratified Partial Likelihood Estimation (SPLE) which itself is a generalization of Cox Partial Likelihood. To start with, we estimate the effects of individual explanatory variables allowing for fixed cluster effects (i.e. semester-specific municipality effects in our case). Denote $\Omega^{j}(d, s)$ the set of individuals at risk in municipality $j$ during semester $s$ for a duration $d$, i.e. the set of all individual unemployment spells which reach at least duration $d$ during semester $s$. 
The risk set of an individual $i$ who resides in municipality $j(i)$ and whose unemployment spell lasts a duration $d_{i}$ until an exit to a job occurs during semester $s_{i}$, is given by $\Re_{i}=\Omega^{j(i)}\left(d_{i}, s_{i}\right)$. An unemployed worker $\ell$ is in the risk set $\Re_{i}$ under three conditions. The unemployed worker $\ell$ should be a resident of municipality $j(i)$; the observed duration of the unemployment spell should be larger than $d_{i}$; the unemployed worker should have been unemployed at least for a duration $d_{i}$ at some date during semester $s_{i}$. Formally, these three conditions can be written: $j(\ell)=j(i)$, $\min \left(d_{\ell}, d_{c \ell}\right) \geqslant d_{i}$ and $t_{0 \ell}+d_{i} \in\left[\tau_{s_{i}}, \tau_{s_{i}+1}\right)$ where $t_{0 \ell}$ is the date of entry and $t_{c \ell}$ is the date of right-censoring for individual $\ell$.

It is useful to go through a simple example to understand the logic of this construction. Figure 7 explains how unemployment spells are considered in each semester. Two unemployment spells are represented and cover three semesters. The first spell begins during semester 2 and lasts $e_{1}$ units of time till the end of this semester. The spell reaches the end of semester 3 after a total duration of $e_{1}+d_{1}$, and continues afterwards. The second spell begins during semester 1 and lasts $e_{2}$ till the end of this semester. It ends in semester 2 after a complete duration of $e_{2}+d_{2}$. The subsamples of individuals at risk during the first three semesters and that we described above are respectively $\{2\},\{1,2\}$ and $\{1\}$. The set of durations during which there is at least one individual at risk during semester 1 is the interval $\left[0, e_{2}\right]$. For semester 2, the set is $\left[0, e_{1}\right] \cup\left[e_{2}, e_{2}+d_{2}\right]$ (where in our example $e_{1}<e_{2}$ ), and for semester 3 , the set is the interval $\left[e_{1}, e_{1}+d_{1}\right]$.

Coming back to the thread of our formal discussion, we now derive the Cox partial likelihood function from the following conditional probability. Individual $i$ finds a job after an unemployment spell of duration $d_{i}$ during semester $s_{i}$, conditionally on the event that someone in individual i's risk set $\Re_{i}$ finds a job at duration $d_{i}$ during semester $s_{i}$, with the probability given by:

$$
P_{i}=P\left(d_{i}, s_{i} \mid \ell \in \Re_{i}, \quad\left(d_{\ell}, s_{\ell}\right)=\left(d_{i}, s_{i}\right)\right)=\frac{\exp \left(X_{i} \beta_{s_{i}}\right)}{\sum_{\ell \in \Re_{i}} \exp \left(X_{\ell} \beta_{s_{i}}\right)}
$$

Observe that since the risk set is defined for each semester and municipality, the baseline hazard 
disappears from this conditional likelihood function. This baseline hazard can thus depend in a flexible way on semester-specific municipality effects. It is in this sense that this method of estimation is stratified.

The sample partial likelihood function can be written:

$$
L=\prod_{i} P_{i}=\prod_{s} L_{s}\left(\beta_{s}\right)
$$

where $L_{s}\left(\beta_{s}\right)=\prod_{i \mid s_{i}=s} P_{i}$ is the partial likelihood function of all individuals experiencing an exit during semester $s$. Note that a given likelihood function $L_{s}$ contains terms relative to some individuals at risk during semester $s$ who do not experience an exit but contribute to the denominator of (2). In contrast, some individuals at risk during semester $s$ may not be used at all to compute the likelihood $L_{s}$. For instance, denote $d_{s 0}$ the smallest duration at which an individual experiences an exit during semester $s$ in a given municipality. If some individuals are at risk in the same municipality during semester $s$ only for durations shorter than $d_{s 0}$, then they are not used to compute $L_{s}$. Finally, note that an individual may contribute to several $L_{s}$ as he may be at risk at some dates in several semesters.

In practice, it is computationally intractable to maximize the full partial likelihood function $L$ when both the sample and the number of semesters are large. As our application has $N=8,831,456$ observations and $S=20$ periods, we perform the estimation on subsamples. We maximize each term $L_{s}$ with respect to $\beta_{s}$ on an adequate subsample which contains all the information and is constructed in the following way. Denote $\Omega_{s}^{j}$ the subset of individuals at risk in municipality $j$ during semester $s$. The subsample of individuals at risk during semester $s$ is then $\Omega_{s}=\underset{j}{\cup} \Omega_{s}^{j}$. The set $\Omega_{s}$ contains all the individuals necessary to compute the partial likelihood functions $L_{s}$. Maximizing each $L_{s}$ separately requires that the coefficients of individual variables in equation (1) are left free to depend on the semester. This was assumed from the start although had we wished, we could have imposed the identity of these coefficients across semesters using minimum distance estimation in a second step. This would have enabled us to obtain coefficients which are constant 
across semesters. We prefer to use the more flexible estimates so that the policy evaluation is robust to varying effects of individual characteristics over the business cycle.

\subsection{Estimating municipality effects}

Given the estimation of coefficients $\beta_{s}$ we can now recover the baseline hazard functions in each municipality and for each semester. Define the integrated baseline hazard function in a munic-

ipality $j$ for semester $s$ as $\Theta_{s}^{j}(d)=\int_{0}^{d} \theta^{j}(u, s) d u$. We construct the Breslow's estimator of this function as:

$$
\widehat{\Theta}_{s}^{j}(d)=\int_{0}^{d} \frac{I\left(C_{s}^{j}(u)>0\right)}{\sum_{i \in \Omega_{s}^{j}(u)} \exp \left(\widetilde{X}_{i} \widehat{\beta}_{s}^{\widetilde{X}}\right)} d N_{s}^{j}(u)
$$

where $\widehat{\beta_{s}^{\widetilde{X}}}$ is the SPLE of $\beta_{s}^{\tilde{X}}, \Omega_{s}^{j}(u)$ is the subset of individuals at risk in municipality $j$ during semester $s$ after duration $u$ (such that we have: $\Omega_{s}^{j}=\cup_{u} \Omega_{s}^{j}(u)$ ), I(•) is the indicator function, $C_{s}^{j}(u)=\operatorname{card} \Omega_{s}^{j}(u)$, and $d N_{s}^{j}(u)$ is a dummy that equals one if someone in municipality $j$ experiences an exit during semester $s$ in an arbitrarily short period of time before date $u$ (and zero otherwise). Moreover, the variance of $\widehat{\Theta}_{s}^{j}(d)$ for each $d$ can be recovered from the formulas given in Ridder and Tunali (1999). Its implementation is also detailed in Gobillon, Magnac and Selod (2010).

Note that we choose not to include the estimates of the $\beta_{s}^{J \prime}$ coefficients (the coefficient of the dummies for months and years of entry) in the computation of the denominator of (4). We do so because the estimates of these coefficients pick up a mixture of the calendar time effects at entry and exit and are not unbiased estimators of the true entry effects. More generally, this stems from the non-identification of duration and entry effects when no functional form is assumed.

Equation (4) yields an estimate of the integrated baseline hazard function for each municipality and semester. We could presumably work with various summaries of these functions, for instance the integrated hazards at 6 months, 12 months, etc., describing the facility with which the unemployed 
find a job in a given municipality. We prefer to summarize the semester-specific municipality effects using a multiplicative specification. The hazard function in a municipality $j$ during semester $s$ takes the form:

$$
\theta^{j}(d, s)=\alpha_{s}^{j} \theta(d)
$$

where $\alpha_{s}^{j}$ is a semester-specific municipality effect and $\theta(d)$ is a general baseline hazard function. To estimate the semester-specific municipality effects, we break down unemployment duration into $M$ intervals $\left[d_{m}, d_{m+1}\right), m=1, \ldots, M-1$ with $d_{1}=0$ and $d_{M}=+\infty$. In our application, the length of each interval is 90 days except the last one which is unbounded on the right. We denote $m$ the interval $\left[d_{m}, d_{m+1}\right)$ and $\theta_{m}=\frac{1}{d_{m+1}-d_{m}} \int_{d_{m}}^{d_{m+1}} \theta(u) d u$ the average baseline hazard rate over interval $m$. The average hazard over a duration interval $m$ in municipality $j$ is given by

$$
y_{s, m}^{j}=\frac{1}{d_{m+1}-d_{m}}\left[\Theta_{s}^{j}\left(d_{m+1}\right)-\Theta_{s}^{j}\left(d_{m}\right)\right] .
$$

We denote:

$$
\Delta_{s, m}^{j}=\int_{d_{m}}^{d_{m+1}} I\left(C_{s}^{j}(u)>0\right) d u
$$

the time in interval $m$ during which some individuals are at risk in municipality $j$ during semester $s$. An estimator of the quantity given in (6) when some people are at risk $\left(\Delta_{s, m}^{j}>0\right)$ can be constructed from equation (4). It is given by: $\hat{y}_{s, m}^{j}=\frac{1}{\Delta_{s, m}^{j}}\left[\widehat{\Theta}_{s}^{j}\left(d_{m+1}\right)-\widehat{\Theta}_{s}^{j}\left(d_{m}\right)\right]$. Using equation (5), we can set up the estimation of this model as a minimum distance procedure by writing that

$$
\ln \hat{y}_{s, m}^{j}=\ln \alpha_{s}^{j}+\ln \theta_{m}+\varepsilon_{s, m}^{j}
$$

where $\varepsilon_{s, m}^{j}=\ln \left(\hat{y}_{s, m}^{j}\right)-\ln \left(y_{s, m}^{j}\right)$ are the residuals describing the sampling variability of estimated hazard rates. The covariance matrix of these residuals can be recovered from the covariance matrix of the estimated integrated hazards given by (4).

Nevertheless, we estimate equation (7) by weighted least squares using a simple system of weights instead of using optimal minimum distance. The poor small sample properties of optimal minimum distance estimation are well known (see for instance Altonji and Segal, 1996, and follow-ups). 
Other weighting schemes are possible and we tested in Gobillon, Magnac and Selod (2010), although with a much more restrictive set of data, the robustness of our results to these alternative weights. Our simple weights are given by the number of unemployed workers at risk at the beginning of each duration interval $m$. Note that this number may not include all individuals of a given municipality that contributed to the partial likelihood $L_{s}$ over the interval. Indeed, some unemployed workers of the municipality may be at risk at semester $s$ inside an interval but not at the beginning of that interval. Finally, we can derive the covariance matrix of the estimator of $\alpha_{s}^{j}$ from the covariance matrix of semester-specific municipality integrated hazards as explained by Ridder and Tunali (1999).

\subsection{Evaluation of the effect of enterprise zones}

We can now finally turn to the evaluation of the effect of enterprise zone designation on the

municipality effects $\alpha_{s}^{j}$ estimated above for each municipality $j$ and semester $s$. These municipality effects describe the facility with which the unemployed find a job in municipality $j$ at semester $s$. We distinguish semesters before the creation of enterprise zones that we generically denote $s_{0}$ (i.e. between the second semester of 1993 and the second semester of 1996) and semesters after the creation of EZs that we generically denote $s_{1}$ (i.e. between the first semester of 1997 and the first semester of 2003). We adopt the vocabulary of treatment effects when referring to enterprise zone designation (Rosenbaum and Rubin, 1983). Denote $\ln \alpha_{s_{1}}^{j}(1)$ the (logarithm of) municipality effect in the case in which municipality $j$ is treated. It is the observed or estimated effect in the case the municipality comprises an enterprise zone in semester $s_{1}$ and the counterfactual if the municipality does not host an enterprise zone in semester $s_{1}$. Similarly, the municipality effect is denoted $\ln \alpha_{s_{1}}^{j}(0)$ when municipality $j$ does not contain an enterprise zone in semester $s_{1}$. It is the counterfactual when municipality $j$ does in fact contain an enterprise zone in semester $s_{1}$. Now, denote $Z^{j}$ the treatment indicator, a dummy variable that indicates whether municipality 
j actually comprises an enterprise zone from 1997 onwards. The observed municipality effect in semester $s_{1}$ can thus be written as:

$$
\ln \alpha_{s_{1}}^{j}=Z^{j} \cdot \ln \alpha_{s_{1}}^{j}(1)+\left(1-Z^{j}\right) \ln \alpha_{s_{1}}^{j}(0)
$$

The average effect of enterprise zone designation on unemployment exits in municipalities which include enterprise zones after 1997-i.e. the treatment on the treated - is given by:

$$
\delta=E\left[\ln \alpha_{s_{1}}^{j}(1)-\ln \alpha_{s_{1}}^{j}(0) \mid Z^{j}=1\right]
$$

This cannot be observed since the term $E\left[\ln \alpha_{s_{1}}^{j}(0) \mid Z^{j}=1\right]$ in this expression is a counterfactual. Assume nevertheless that the change in the municipality effects over time would have been the same for treated and non-treated municipalities in the absence of the treatment giving:

$$
E\left[\Delta \ln \alpha^{j}(0) \mid Z^{j}=1\right]=E\left[\Delta \ln \alpha^{j}(0) \mid Z^{j}=0\right]
$$

where we denote $\Delta \ln \alpha^{j}(z)=\ln \alpha_{s_{1}}^{j}(z)-\ln \alpha_{s_{0}}^{j}$ with $z \in\{0,1\}$. The effect of creating an enterprise zone can now be rewritten as:

$$
\begin{aligned}
\delta & =E\left[\Delta \ln \alpha^{j}(1)-\Delta \ln \alpha^{j}(0) \mid Z^{j}=1\right] \\
& =E\left[\Delta \ln \alpha^{j}(1) \mid Z^{j}=1\right]-E\left[\Delta \ln \alpha^{j}(0) \mid Z^{j}=1\right] \\
& =E\left[\Delta \ln \alpha^{j}(1) \mid Z^{j}=1\right]-E\left[\Delta \ln \alpha^{j}(0) \mid Z^{j}=0\right],
\end{aligned}
$$

where the definitions of first differences were used to obtain the first line, and where assumption (8) was used to obtain the third line.

The first right-hand side term in (9) can be estimated from the data on treated municipalities using the formula:

$$
\widehat{E}\left[\Delta \ln \alpha^{j}(1) \mid Z^{j}=1\right]=\sum_{j \mid Z^{j}=1} \omega_{j}\left[\widehat{\ln \alpha_{s_{1}}^{j}}-\widehat{\ln \alpha_{s_{0}}^{j}}\right]
$$

where $\omega_{j}$ is a weight and $\widehat{\ln \alpha_{s}^{j}}$ is an estimator of the semester-specific municipality effect (which is estimated in the previous stage). In practice, the weight can be constructed using the share of un- 
employed workers living in a treated municipality $j$ or using the covariance matrix of municipality effects obtained in previous stages.

Similarly, the second right-hand side term in (9) can be recovered likewise from the data on untreated municipalities:

$$
\widehat{E}\left[\Delta \ln \alpha^{j}(0) \mid Z^{j}=0\right]=\sum_{j \mid Z^{j}=0} \omega_{j}\left[\widehat{\ln \alpha_{s_{1}}^{j}}-\widehat{\ln \alpha_{s_{0}}^{j}}\right] .
$$

An estimator of the effect of enterprise zone designation is then given by:

$$
\widehat{\delta}=\widehat{E}\left[\Delta \ln \alpha^{j}(1) \mid Z^{j}=1\right]-\widehat{E}\left[\Delta \ln \alpha^{j}(0) \mid Z^{j}=0\right]
$$

In practice, as we will see below, $\widehat{\delta}$ is the estimated coefficient of the treatment indicator in a regression weighted by $\omega_{j}$ of semester-specific municipality effects on dummies for municipalities, dummies for time intervals, and the treatment indicator.

Interestingly, estimates can be obtained using versatile definitions of the control group. When defining the control group however, there is a potential conflict between two objectives. First, we aim at retaining municipalities that are similar to those in the treatment group along various dimensions. This suggests that the control group should comprise municipalities that are closest in the space of characteristics, including the location within the Paris region (i.e. neighbor municipalities). Observe that since political actors had a say in the designation of enterprise zones, the selection process was not completely based on the ranking according to the aggregate indicator. This makes it easier to find control municipalities with characteristics similar to those that are treated. Nonetheless, avoiding contamination of the effects through spatial spillovers is a second objective and this may contradict the first objective (Blundell, Costa-Dias, Meghir and van Reenen, 2006). This is why it makes sense to develop various empirical strategies controlling for various municipality variables and various ways of constructing the control group. 


\section{Results of the policy evaluation}

To start with, we briefly report the results of the estimation of the stratified Cox model which allows us to estimate spatial effects free of "composition effects" due to individual observed characteristics. We then turn to the evaluation of the creation of enterprise zones on January 1st 1997. We begin with defining the treatment parameter and with reporting the estimation of the propensity score at the municipality level. We then present estimates obtained by matching, within and first difference estimation. We finally report our preferred specification and provide various robustness checks.

\subsection{Stratified partial likelihood estimates}

We performed the first-stage estimation of the model as given by the partial likelihood (3) for

all semesters between the second semester of 1993 and the first semester of 2003. In Table 4, we report only the results of this estimation for the first semester of 1994 and the first semester of 2000. In our policy evaluation, this first-stage is used to purge semester-specific municipality rates of exit to a job from individual composition effects and to control for right-censorship in durations. The effects of socio-demographic characteristics are very similar to those that were obtained in Gobillon, Magnac and Selod (2010) where we used a single flow sample instead of semester specific samples. We refer the reader to this paper for a full analysis of these effects although a brief summary is useful. Unemployed workers who are disabled, who are females or who have many children, less often experience an exit to a job. Those living in a couple exit to a job more often and as expected low educated unemployed workers exit to a job less often than educated ones. Furthermore, Sub-Saharan Africans and North Africans find a job far less often than French people. Noticeably, the situation deteriorated between 1994 and 2000 for low educated people and Sub-Saharan Africans. This confirms that rates of exit to a job decreased 
over this period, specifically for the sub-populations who experience a low exit rate.

\section{[Insert Table 4]}

\subsection{Definition of the treatment}

We estimate the effect of the EZ program using various dates before and after the creation of EZs. In the setting of Section 5.3, the period $s_{0}$ now corresponds to all semesters between the second semester of 1993 and the second semester of 1996 (semester 7 on the Figures) and $s_{1}$ corresponds to all semesters between the first semester of 1997 (semester 8) and the first semester of 2003.

The treatment group is composed of municipalities which comprise an enterprise zone. In robustness checks we shall also test our results against departures from this construction and will distinguish municipalities for which enterprise zones represent a large section of their population (more than 50\%) from the other treated municipalities. We will also modify the treatment group by including neighbors of treated municipalities.

The main substantive issue concerns the control group which in principle could contain all municipalities which are not in the treatment group. However, this implicitly assumes that all non-treated municipalities resemble treated municipalities, which is far from being the case. Some municipalities are too far from the treated municipalities both geographically or in the space of other characteristics. Most prominently, the population size of a municipality has a very different support in the primary treatment and control groups. While the control group comprises many small and very small municipalities (less than 1,000 inhabitants), the smaller population size of a treated municipality is 17,500 . We thus chose from the start to restrict the control group to municipalities whose population size is between 8,000 and $100,000 .{ }^{10}$ Note that it changes the

\footnotetext{
${ }^{10}$ The reason for excluding the municipalities over 100,000 inhabitants is that this group includes Paris inner districts and one close neighbor, Boulogne-Billancourt, which are at no risk of being selected because of their affluence. We chose the lower bound of 8,000 because we wanted to include neighbors of treated municipalities. We do not know the identity of unsuccessful applicants to the program.
} 
definition of the treatment parameter which now refers to municipalities with this population size.

Further restrictions on the control group will further modify the definition of the "effect of a treatment" and will be brought in after the construction of the propensity score that we now detail.

\subsection{Describing the treated municipalities: the propensity score}

We now analyze the municipality characteristics that determine the creation of an enterprise zone and that will allow us to construct the propensity score as proposed by Rosenbaum and Rubin (1983) so as to control for selection on observables. We estimate a discrete model, here Probit, to explain the status of being designated, $z=1$ against $z=0$ where we use some municipality control variables $X$ among which are measures of physical job accessibility, the municipal composition of the population in terms of nationality or education, the rate of unemployment, the proportion of young adults, and the fiscal potential. We also include in the specification the smallest distance to another municipality comprising an enterprise zone. This is to account for the possible will of authorities to spread enterprise zones more or less evenly throughout the region. ${ }^{11}$ Results of weighted Probit estimations where the weights are the (square root of the) population size of unemployed workers in the municipality are reported in Table 5. The results of our benchmark and preferred specification appear in the first column although some less parsimonious specifications were also estimated (see the notes below this Table).

\section{[Insert Table 5]}

In conformity with the selection criteria, the larger the fiscal income in the municipality or the smaller the proportion of persons without a high school diploma in the municipality, the less likely the municipality comprises an enterprise zone although the latter effect is hardly significant. The

\footnotetext{
${ }^{11}$ We checked endogeneity issues by experimenting with the second-lowest distance as an instrument. It hardly affected results.
} 
higher the rate of individuals below 25 or the larger the size of the population, the larger the probability that the municipality contains an enterprise zone. In terms of distance, the larger the distance to a designated municipality or the larger the density of jobs attainable in less than 60 minutes by private vehicle, the less likely it is that the municipality will be endowed with an enterprise zone. This is consistent with the targeting of places with relatively lower job accessibility. Also, since designated areas are clustered around Paris, they all have another designated area as a close neighbor, explaining the negative sign on the distance to the nearest EZ (although not significant). In line with Hanson (2009), we also experimented with political variables which are the frequency of votes for political parties. Even if municipalities whose townhalls were administered by politicians belonging to the governing party at the time of EZ designation are more likely to be picked up, the effect is not significant and we chose not to include these variables in the final specification.

In the two other columns of Table 5, we experimented two alternatives. We first included a variable equal to the average of municipality effects affecting exit rates to a job in the semesters before the implementation of the policy (as estimated in the first step by Stratified Partial Likelihood). We chose the average of these effects because the average was the most significant predictor of the propensity score. The effect is positive although it is at the limit of significance. This means that the municipalities including a designated area seem to be more advantaged in term of easiness for exiting unemployment than the other municipalities sharing the same local characteristics. This is a standard result in the evaluation literature where governments often intervene to "pick winners" (Boarnet and Bogart, 1996). We also ran the Probit regression using no weights and though standard errors are larger, the effect of variables remains qualitatively the same. We will test later for the robustness of our complete results to these changes in specification.

Using the results in column 1, we predict the propensity score for each municipality. It interestingly reveals that the supports of the predicted propensity scores in the treated and control 
groups differ quite markedly as shown in Table 6.

\section{[Insert Table 6]}

The smallest predicted probability in the treatment group is equal to $0.1 \%$. We therefore further restrict the control group to municipalities whose predicted propensity scores are larger than the value $0.05 \%$ (see Table 6). It is roughly two times smaller than the unrestricted control group and includes 135 municipalities (instead of 258), which is equal to about ten times the number of treated municipalities (13). We will later test the robustness of our results to more or less restrictive selections.

\subsection{Matching, within and first-differences}

We chose to estimate linear models of treatment effects given that the number of treated municipalities is quite small (13) with respect to the number of controls (135). As explained in the econometric section and following Imbens and Wooldridge (2009), we started from the following baseline regression :

$$
\widehat{\ln \alpha_{s}^{j}}=\delta Z_{s}^{j}+X_{j} \beta+\alpha_{s}+\alpha^{j}+u_{s}^{j}
$$

where $s$ is the semester, $j$ a municipality and $u_{s}^{j}$ is an error term (including the sampling error on the left-hand side variable due to first-stage estimation). Parameters $\alpha_{s}$ denote time dummies

(for semesters) and $\alpha^{j}$ is a municipality effect. Variable $Z_{s}^{j}$ is the dummy for treatment status, $X_{j}$ are control variables which do not vary across time in our database.

Using an orthogonality argument of Rosenbaum and Rubin (1983), we have:

$$
E\left(u_{s}^{j} \mid Z_{s}^{j}, X_{j}\right)=0 \Longrightarrow E\left(u_{s}^{j} \mid Z_{s}^{j}, X_{j}, p\left(X_{j}\right)\right)=E\left(u_{s}^{j} \mid Z_{s}^{j}, p\left(X_{j}\right)\right)=0
$$

Hence, we can replace from now on the explanatory variables by the propensity score $p\left(X_{j}\right)$ although we experimented with general specifications. 
The regression set-up (11) delivers the parameter of interest, $\delta$, which is equal to the average treatment on the treated. A natural weight to use is the number of unemployed workers in the municipality at the beginning of each semester. We shall also check the robustness of the results using alternative weights such as the inverse of the estimated standard error of the estimate $\widehat{\ln \alpha_{s}^{j}}$.

An important aspect of the specification is the inclusion of a full set of time-constant municipality effects, $\alpha^{j}$, in regression (11). Nevertheless, we can start from a more parsimonious form where we only include the indicator variable that a municipality comprises a designated enterprise zone, so that $\alpha^{j}=\alpha^{D} . \mathbf{1}\{j$ is designated $\}$. This restriction grants more identification power when estimating $\delta$ in equation (11) at the cost of reinforcing the restrictiveness of the orthogonality condition described by equation (12). We shall see that this restrictive condition is rejected by the data and that a full set of municipality effects is needed.

We first run a basic regression without any controls whose results are reported in Table 7 , column (1). The effect of the dummy for including a designated area, $\alpha_{D}$, is negative and significant which confirms that in a treated municipality, the unemployed are receiving and accepting a job with a lower probability. Our parameter of interest, the treatment parameter, is estimated to be negative but insignificantly different from zero. It does not seem to be an issue stemming from large standard errors since the order of magnitude of the standard error is approximately the same as for the previous designation effect.

\section{[Insert Table 7]}

To go further, we introduce the propensity score as it was estimated in Table 5 column (1) and Table 7 column (2) reports the results. Firstly, the coefficient of the predicted propensity score is strongly significant and negative. Potentially treated municipalities have a significantly lower exit rate to employment. Secondly, note that the sign of the coefficient of a designated municipality effect, $\alpha_{D}$, changes in comparison with column (1): it is now positive and very significant. Enterprise zones were created in municipalities where the chances of finding a job 
are significantly larger when holding constant the characteristics that explain the treatment i.e. through the propensity score. It confirms the effect of "picking winners" that we identified from the results on the propensity score in Table 5. In contrast, controlling for the propensity score does not affect the estimate of $\delta$. It remains insignificantly different from zero at the $10 \%$ level and a large standard error is not responsible for the lack of impact. We also experimented with a more flexible specification for the propensity score using splines without any substantial effect as reported in column (3) of Table 7 . Finally, we obtain the same results when we use the subsample of larger predicted propensity scores only, municipalities being selected if they are above the 10th percentile of the propensity score in the treatment group.

Our next step is to present results when we include unrestricted municipality effects, $\alpha^{j}$. There are two common ways to proceed and they should yield the same results if the econometric model is correctly specified. They consist in the use of within estimation or first-differences to eliminate the municipality effects (see for instance Blundell and Costa-Dias, 2009). These estimates are reported in Table 8 where the first column repeats the matching results from Table 7 , the second column reports results of the within estimation using robust-to-heteroskedasticity standard errors and the last column reports results in first differences using robust-to-heteroskedasticity standard errors. $^{12}$

Differences across estimation methods are striking as can be seen on Table 7 . While the estimated coefficient for the treatment indicator in within estimation remains negative at about the same level as the matching estimate, this estimate is significant at the $10 \%$ level. In sheer contrast, the estimate of the treatment parameter using first differences is positive (0.049) and significant at the $1 \%$ level. However, these estimators should converge to the same value. Our econometric model in which the treatment parameter is constant over time is thus rejected by the

\footnotetext{
${ }^{12}$ None of the standard errors are corrected for autocorrelation because this will be done in the next section in a more general context. These corrections are likely to be more severe in first difference estimation.
} 
data.

\section{[Insert Table 8]}

Given our long period of observation, we can plausibly argue that the assumptions underlying difference-in-differences are not valid and that medium-term trends are different in treated and control municipalities. This is why we perform the same analysis by matching, within and firstdifferences although we now allow the treatment parameters to vary period by period after the treatment. Table 9 reports such results and shows that indeed the effect of the treatment seems to have a negative trend using all methods of estimation. The short-run treatment effects as estimated by matching and within estimation are now positive although insignificant in the semester after treatment. They are either positive or negative but still insignificant after the implementation of the treatment. After semester 14, that is after the first semester of 2000, the effects estimated by matching and within estimation are all negative and some of them are significant.

\section{[Insert Table 9]}

In contrast, most effects using first differences are positive and larger in the short run than in the medium term (at least until semester 16) and confirm results obtained in Table 8. Estimated treatment effects are consistently in the range 0.025-0.059 for periods before semester 14 although only two of these estimates are significant. ${ }^{13}$ In contrast, estimates become smaller or negative after semester 14 but grow again after semester 17 . There are therefore two reasons to think that our global evaluation relies too much on the medium run evaluation after semester 14. From Figures 1 and 2, we know that unemployment started trending upward at around semester 14 and that, more importantly, the exit rate from unemployment attributable to unknown exits changed significantly from period 13 onwards. This is why we now restrict our analysis to periods 1 to 12 , between the second semester of 1993 and the first semester of 1999, a period in which the exit rate to a job decreases, the unemployment rate is stable or decreases moderately and the rate of

\footnotetext{
${ }^{13}$ Correcting for autocorrelation affects standard errors (see below).
} 
exits for unknown reasons is stable. We do not take a stand on whether the treatment effects would disappear after three years or whether the implicit underlying assumption of the differencein-differences method about common period effects between treated and control municipalities would be wrong.

\subsection{Our preferred specification}

Table 10 reports results of first difference estimation correcting for within-municipality autocorrelation by FGLS using an unrestricted covariance matrix between semester-specific municipality shocks over time. We present results that we obtain when varying the range of semesters used in the estimations. ${ }^{14}$

\section{[Insert Table 10]}

The first column reports the results of our preferred specification since this specification is robust to various changes in the underlying construction and seems to be a conservative estimate. The estimated treatment parameter is equal to .031 and is significant at the $5 \%$ level. This effect is quite small since it implies that the rate of exit to a job increased by a meagre $3 \%$ when the policy was implemented. Given that there are roughly 300 exits each semester in an average municipality in the considered range of population size, the policy amounts to generating about 10 new exits per semester only.

We included as an explanatory variable the propensity score to control for any residual unobserved municipality heterogeneity. ${ }^{15}$ It amounts to considering that municipalities could have heterogeneous trends in their exit rates, something which might be more likely in a period in which exit rates to a job have a strong downward trend (between the second semester of 1993 and the first semester of 2000, see Figure 2). These trends are supposed to be random conditional

\footnotetext{
${ }^{14}$ We do not report the estimated semester effects. They reproduce closely the raw trends as graphed in Figure 2 .

${ }^{15}$ We did not correct for the generated regressor issue that such an inclusion implies.
} 
on observables (Heckman and Hotz, 1989) so that a much less restrictive orthogonality condition than equation (12) holds, namely:

$$
E\left(u_{s}^{j}-u_{s-1}^{j} \mid Z_{s}^{j}, p\left(X_{j}\right)\right)=0 .
$$

This assumption was exploited by Heckman, Ichimura and Todd (1997) and this approach belongs to matching difference-in-differences methods as described by Blundell and Costa-Dias (2009). We use it in a linear regression setting because our samples are small.

In the second column we further restrict the period of evaluation, keeping only two semesters before the reform and two semesters after the reform. The estimate remains significant and stands at .042. If we further restrict to the period at which the reform was implemented, the estimate is equal to .035 although it becomes insignificant. The treatment variable is very much correlated with the propensity score and when we omit the latter, the estimate increases to .058 and is significant at the $1 \%$ level, which corresponds to a significant doubling of the effect. It might however reflect that some firms delayed hiring during the last semester of 1996 in order to benefit from the policy in the following semester although we do not find evidence of such opportunism below.

Interestingly, we can distinguish between treated municipalities according to the proportion of the municipality population which resides within the enterprise zone. Specifically, we included in our preferred specification an indicator that the proportion of the population living in the enterprise zone in the treated municipality is below $50 \%$. The result is striking since the treatment parameter estimate is now equal to .057 instead of .031 and is significant at a $1 \%$ level while the treatment effect in municipalities where a small proportion of the population lives in an enterprise zone is also positive $(.016=.057-.041)$ but becomes insignificant. The dilution of the effect will be confirmed below when changing the treatment definition. It points out that the effect of the policy is very localized. 


\subsection{Spillover effects}

We now investigate the possibility of spatial spillovers on neighboring municipalities. In theory, spatial spillovers for neighboring areas can either be positive (if workers in neighboring areas benefit from the expansion of the activity in the EZ) or negative (if jobs are relocated away from neighboring areas, or if some substitution of non-EZ jobs with EZ jobs occur). A "positive" externality on non-EZ areas may occur if the policy adversely leads to the stigmatization of EZ residents, with employers discriminating against EZ residents and becoming more likely to hire workers residing outside the EZ.

To assess these effects, we began with changing the composition of the control group. We selected municipalities in the control group depending on their distance to a treated municipality. We experimented with three distance thresholds at 5, 10 and 15 kilometers where these distances are taken between municipality centres. We first restricted the previous control group to municipalities whose center is farther than 5 kilometers of the center of a treated municipality (respectively 10 and 15 kilometers). Second, we restricted the control group to municipalities whose center is within 5 kilometers of the center of a treated municipality (respectively 10 and 15). Table 11 reports these results.

[Insert Table 11]

The evidence of spillover effects to neighboring municipalities is weak. In all but one of these experiments, the estimates of the treatment parameter remains around .03 although with some degree of variation in the significance of the estimates. The only case in which the estimate becomes hardly distinguishable from zero is when the control group is restricted to municipalities outside the $15 \mathrm{~km}$ range of a treated municipality. In our opinion, the assumption that these municipalities are affected by the same period effects as the treated municipalities becomes unsustainable since these municipalities correspond to distant zones where the labor market conditions are likely to be different. 
We also attempted to change the definition of the treatment, and the composition of the treatment and control groups. Instead of retaining the municipalities comprising an enterprise zone only, we also retained their neighbors at a distance of less than 2 kilometers (respectively at a distance of less than 3 kilometers). The number of potentially treated municipalities increases from 13 to 24 treated municipalities (respectively 51). Table 12 reports these results. It is striking that in both cases the estimated treatment parameter is no longer significantly different from zero. It confirms that the creation of an enterprise zone has a very localized effect on the unemployment exit rate to a job as was already seen in Table 10. It has no significant spillover effects on neighboring municipalities.

\section{[Insert Table 12]}

\subsection{Other robustness checks}

We also performed other robustness checks of these results. First, we modified the whole procedure so as to include the past average of municipality effects in the propensity score. Second, we varied the municipality-and-semester specific weights that we used in the estimation. Instead of using the (square root of the) number of unemployed workers in the municipality at the beginning of the semester, we used the (inverse) standard errors of the estimates of the left-hand side variable as provided by the first-stage estimates or no weights at all. Table 13 presents these results which are hardly different from those obtained for the main specification and if anything, estimates of the treatment parameter are becoming larger.

\section{[Insert Table 13]}

Moreover, the construction of the semester-specific municipality effects purges exit rates to jobs from individual characteristics although it does a poorer job at controlling for entry effects because of identification issues. We included year and month dummies in the first stage estimation notwithstanding that identification of these parameters from baseline duration hazard could be 
fragile. This is why we re-estimated our preferred specification controlling for semester and municipality specific entry rates. Results are presented in the first two columns of Table 14. In the first column (respectively the second column), we control for the log-entry rate in the current period (resp. the lagged log-entry rate). Although this variable has a significant and positive (resp. negative and not significant) effect, the estimate of the treatment effect is hardly affected and remains equal to approximately .03.

\section{[Insert Table 14]}

Lastly, to measure placebo effects, as suggested by Manning and Pischke (2006) we also included in the specification an indicator for the lagged treatment effect. If the policy is anticipated, however, a negative effect could be observed if employers delay hiring decisions. The lagged treatment effect is found not to be significantly different from zero and not to affect the estimated treatment parameter.

\subsection{Policy evaluation of related outcomes}

We also performed the same evaluation using as dependent variable the raw entry rates into unemployment as in Papke (1994) and the three raw exit rates from unemployment that we can construct from our data. Recall indeed that an exit can have three different destinations: a job, non-employment or an unknown reason.

We check whether the results with raw rates are comparable with those obtained by applying

our more sophisticated method that purges exit rates to a job from individual characteristics and takes into account the usual censorships that affect unemployment data. This is a useful check to perform since policy analysts often resort to raw rates to perform policy evaluations. Table 15 reports these results.

$$
\text { [Insert Table 15] }
$$

In column 1, the parameter which measures the effect of the treatment on the log-entry rates in 
unemployment is not significantly different from zero. Column 2 reports the effect of the treatment on the log-exit rates out of unemployment to a job. It is significantly positive and equal to .040. It is thus slightly larger than the estimate that we obtain using our two step procedure to purge exit rates from composition effects (in terms of observed individual characteristics) although the difference is insignificant. The difference may come either from composition effects or from rightcensored unemployment spells. In the somewhat restricted sense that the conclusion applies to this specific dataset, it suggests that the estimates using raw data could in fact be reasonable approximations.

Evidence gathered in Tables 14 and 15 runs against an argument advanced by Elverly (2009) about indirect effects of employment zones. The local labour market in treated municipalities would become more attractive after the creation of an enterprise zone and non-employed persons would be encouraged to search for a job. This would increase the entry rate into unemployment and the competition for jobs among the unemployed. We neither find that the treatment parameter is affected by entry rates (Table 14) nor that entry rates change because of the program (Table 15).

The estimates of the treatment parameter for exits to non-employment and exits for unknown reasons are not significantly different from zero although the estimate for exits to non-employment is quite large at the same level .039. Contrary to the stylized facts in the descriptive section above, the censorship due to exits for unknown reasons does not seem to be affected by the policy. Our estimated parameter is thus robust to the consideration that some exits for unknown reasons might be exits to a job triggered by the EZ policy.

\section{Conclusion and policy discussion}

In this paper, we have evaluated the effects of enterprise zones in the Paris region on exit rates from unemployment to employment at the municipality level.

Our main results are threefold. Firstly, in line with several studies on enterprise zones, we 
showed that zone designation tended to favor municipalities with favorable unobserved characteristics. This is not surprising given that policy makers usually tend to select places that are more likely to carry success or choose places that gather prior favorable conditions for economic development. Secondly, we found that the French EZ program had a small positive impact, which is consistent with previous work on the number of local establishments in enterprise zones (Rathelot and Sillard, 2009). The policy had a short-run impact on the ease with which the local unemployed workers move out of unemployment. This result is robust to a variety of specifications and robustness checks and is broadly in line with the previous works in the US that found that enterprise zones had a small impact on employment (Papke, 1994, Lynch and Zax, 2008, Neumark and Kolko, 2010) and contrasts with those which found that it had no impact on employment (Boarnet and Bogart, 1996, Bondonio and Engberg, 2000). Lastly, we find that the effect is very localized and seems to be the direct consequence that tax rebates are given in exchange of the requirement that some locals should be hired.

The estimated effect of the policy on unemployment is small and represents a $3 \%$ increase in the rate of exit from unemployment to jobs. This is in contrast with the figure of a $30 \%$ increase in the number of jobs in the treated EZ reported by Gilli (2006) for the same period. This suggests that the substitution of jobs from non-EZ to EZ areas may indeed have been quite large but may have had an overall effect on employment that was almost neutral. It is also likely that the policy may have tended to stimulate exits from non-employment -which we are not able to measure with our data. Finally, external effects on non-economic outcomes may also have been triggered by the EZ policy. We leave these issues for future research. 


\section{References}

[1] Altonji J.G. and L.M. Segal (1996), "Small sample bias in GMM estimation of covariance structures". Journal of Business \& Economic Statistics, 14, 353-565.

[2] André P. (2002) "Rapport d'information fait au nom de la commission des Affaires économiques et du plan sur les zones franches urbaines", $N^{\circ} 354$, Sénat, Session extraordinaire de 2001-2002

[3] Blundell, R. and M. Costa-Dias, 2009, "Alternative Approaches to Evaluation in Empirical Microeconomics", Journal of Human Resources, 44(3), Summer, 565-640.

[4] Blundell, R., M. Costa-Dias, C.Meghir and J.van Reenen (2004), "Evaluating the Employment Impact of a Mandatory Job Search Assistance Program", Journal of European Economic Association, 2(4), 596-606.

[5] Boarnet M. and W. Bogart (1996) "Enterprise Zones and Employment: Evidence from New Jersey", Journal of Urban Economics, 40, 198-215.

[6] Bondonio D. and R. Greenbaum (2007) "Do Local Tax Incentives Affect Economic Growth? What Mean Impacts Miss in the Analysis of Enterprise Zone Policies", Regional Science and Urban Economics, 37, 121-136.

[7] Bondonio D. and J. Engberg (2000) "Enterprise Zones and Local Employment: Evidence from the States' Programs", Regional Science and Urban Economics, 30, 519-549.

[8] Bostic R. and A. Prohofsky (2006) "Enterprise Zones and Individual Welfare: A Case Study of California", Journal of Regional Science, 46, 2, 175-203.

[9] Busso M. and P. Kline (2008), "Do Local Economic Development Programs Work? Evidence from the Federal Empowerment Zone Program", Yale Economics Department Working Paper 36.

[10] Carrol D. and J. Ross (2006) "California's Enterprise Zones Miss the Mark", a publication of the California Budget Project. 
[11] Choffel P. and E. Delattre (2003) "Habiter un quartier défavorisé : quels effets sur la durée du chômage?", Premières Synthèses, Dares, n43.1.

[12] DIV - Ministre Délégué à la Ville (2001) "Bilan des Zones franches urbaines". Rapport au Parlement.

[13] DIV - Ministre Délégué à la Ville (2004), Observatoire National des Zones Urbaines Sensibles, Rapport 2004.

[14] Elvery J. (2009), "The Impact of Enterprise Zones on Resident Employment: An Evaluation of the Enterprise Zone Programs of California and Florida", Economic Development Quaterly, $23(1), 44-59$.

[15] Ernst, 2008, "L'activité économique dans les ZFU", INSEE Première, 1187 (May).

[16] Fisher P. an,d A. Peters (1997) "Tax and Spending Incentives and Enterprise Zones", New England Economic Review, March/April, 109-137.

[17] Gilli F. (2006)" Enterprises et développement urbain : les zones franches ont-elles rempli leur mission ?", in Les Entreprises Françaises en 2006, de Boissieu and Deneuve (eds.), Economica, chapter 10, 163-187.

[18] Gobillon L. and H. Selod (2008) Les déterminants locaux du chômage en région parisienne (in French), Economie et Prévision, 180-181 4/5, 19-38.

[19] Gobillon L., Magnac T. and H. Selod (2008) "Spatial Disparities in Exit from Unemployment: Low-Skilled Workers and Foreigners in the Paris Region", mimeo.

[20] Gobillon L., Magnac T. and H. Selod (2010) "The Effect of Location on Finding a Job in the Paris Region", forthcoming Journal of Applied Econometrics.

[21] Hasluck C., Elias P. and A. Green (2003) "The Wider Labour Market Effects of Employment Zones", Department for Work and Pensions Research Report W175.

[22] Hanson A. (2009) Local employment, poverty, and property value effects of geographicallytargeted tax incentives: An instrumental variables approach, Regional Science and Urban Economics, 39, 721-731. 
[23] Heckman, J.J. and V. J. Hotz (1989), "Choosing Among Alternative Nonexperimental Methods for Estimating the Impact of Social Programs: The Case of Manpower Training", Journal of the American Statistical Association, 84, 862-874.

[24] Heckman, J., Ichimura H. and P.Todd (1997), "Matching as an Econometric Evaluation Estimator: Evidende from Evaluating a Job Training Programme", Review of Economic Studies, 64, 605-654.

[25] Hirasuna D. and J. Michael (2005) "Enterprise Zones: A Review of the Economic Theory and Empirical Evidence", Policy Brief - Minnesota House of Representatives - Research Department.

[26] Imbens, G. and J., Wooldridge, (2009), "What's new in econometrics", NBER.

[27] Ladd H. (1994), "Spatially Targeted Economic Development Strategies: Do They Work?", Cityscape, 1, 1, 193-218.

[28] Lynch D. and J. Zax (2008), "Incidence and substitution in Enterprise Zone Programs: The case of Colorado", unpublished manuscript.

[29] Manning, A. and J.-S. Pischke (2006), "Comprehensive versus Selective Schooling in England in Wales: What Do We Know?", CEPR Discussion Paper No. 5653.

[30] Mauer D. and S. Ott (1999) "On the Optimal Structure of Government Subsidies for Enterprise Zones and Other Locational Development Programs", Journal of Urban Economics, 45, 421-450.

[31] Neumark D. and J. Kolko (2010), "Do enterprise zones create jobs? Evidence from California's enterprise zone program", Journal of Urban Economics, forthcoming.

[32] O'Keefe S. (2004) "Job Creation in California's Enterprise Zones: A Comparison Using a Propensity Score Matching Model", Journal of Urban Economics, 55, 131-150.

[33] Papke L. (1994) "Tax Policy and Urban Development. Evidence from the Indiana Enterprise Zone Program", Journal of Public Economics, 54, 37-49. 
[34] Peters A. and P. Fisher (2004) "The Failures of Economic Development Incentives", Journal of the American Planning Association, 70, 27-37.

[35] Rathelot R. and P. Sillard (2009), "Zones Franches Urbaines : quels effets sur l'emploi salarié et les créations d'établissements?", Economie et Statistique, 415-416, 81-96.

[36] Ridder G. and I. Tunali (1999) "Stratified partial likelihood estimation", Journal of Econometrics, 92(2), 193-232.

[37] Rosenbaum P. and D. Rubin (1983) "The Central Role of the Propensity Score in Observational Studies for Causal Effects", Biometrika, 70, 41-55.

[38] Rogers C. and J. Tao (2004) "Quasi-Experimental Analysis of Targeted Economic Development Programs: Lessons from Florida", Economic Development Quarterly, 18, 3, 269-285.

[39] Smith, J.A.. and P. Todd (2005), "Does Matching Overcome LaLonde's Critique of Nonexperimental Estimators", Journal of Econometrics, 125, 305-353.

[40] Thélot H. (2004) "Les embauches en zone franche urbaine en 2002", Premières Informations, Premières Synthèses, N³5.1. 
Table 1: Descriptive statistics of the exhaustive sample, by semester

\begin{tabular}{|c|c|c|c|c|c|}
\hline \multirow[b]{2}{*}{ Year } & \multirow[b]{2}{*}{ Semester } & \multicolumn{2}{|c|}{ All municipalities } & \multicolumn{2}{|c|}{$\begin{array}{l}\text { Municipalities whose population is } \\
\text { between } 8,000 \text { and } 100,000 \text { in } 1990\end{array}$} \\
\hline & & Nb. at risk & Exit to job & Nb. at risk & Exit to job \\
\hline 1993 & 2 & $1,139,991$ & 127,748 & 795,570 & 89,404 \\
\hline 1994 & 1 & $1,144,764$ & 144,094 & 799,234 & 100,743 \\
\hline 1994 & 2 & $1,201,196$ & 140,438 & 837,624 & 98,051 \\
\hline 1995 & 1 & $1,153,306$ & 140,389 & 802,327 & 98,364 \\
\hline 1995 & 2 & $1,168,106$ & 135,768 & 813,158 & 94,885 \\
\hline 1996 & 1 & $1,131,391$ & 139,655 & 790,664 & 97,521 \\
\hline 1996 & 2 & $1,171,410$ & 123,759 & 818,334 & 86,350 \\
\hline 1997 & 1 & $1,111,631$ & 124,091 & 778,704 & 86,490 \\
\hline 1997 & 2 & $1,140,782$ & 111,852 & 800,008 & 77,843 \\
\hline 1998 & 1 & $1,090,633$ & 114,619 & 768,067 & 79,910 \\
\hline 1998 & 2 & $1,122,653$ & 102,765 & 791,357 & 71,850 \\
\hline 1999 & 1 & $1,085,102$ & 105,976 & 765,103 & 73,381 \\
\hline 1999 & 2 & $1,101,209$ & 100,188 & 776,471 & 70,061 \\
\hline 2000 & 1 & $1,026,096$ & 103,761 & 723,854 & 72,330 \\
\hline 2000 & 2 & 970,200 & 95,736 & 687,451 & 67,035 \\
\hline 2001 & 1 & 905,301 & 86,233 & 640,140 & 60,183 \\
\hline 2001 & 2 & 936,464 & 76,388 & 661,347 & 53,769 \\
\hline 2002 & 1 & 960,918 & 77,619 & 678,313 & 54,336 \\
\hline 2002 & 2 & $1,061,983$ & 79,513 & 747,329 & 55,657 \\
\hline 2003 & 1 & $1,074,594$ & 77,036 & 755,211 & 53,521 \\
\hline
\end{tabular}

Nb. at risk: number of unemployed workers whose unemployment spell began within the four-year period before the beginning of the semester and who are at risk at least one day during the semester.

Exit to job: number of unemployed workers exiting to a job during the period. 
Table 2: Descriptive statistics of the sample at risk in the first semester of 1994

\begin{tabular}{lrrr}
\hline \hline Variable & N.Obs. & Mean & Std \\
\hline Exit types and unemployment spells & & & \\
Exit to job in the period & $1,144,762$ & 0.126 & 0.476 \\
Exit to non-employment in the period & $1,144,762$ & 0.058 & 0.373 \\
Unknown exit in the period & $1,144,762$ & 0.196 & 0.551 \\
Duration if exit to job in the period & 144,092 & 234.810 & 560.812 \\
Duration if exit to non-employment in the period & 66,196 & 275.532 & 733.689 \\
Duration if unknown exit in the period & 224,829 & 207.517 & 584.673 \\
Characteristics of unemployed workers & & & \\
Age & & & \\
Male & $1,144,762$ & 33.010 & 9.394 \\
Female & $1,144,762$ & 0.522 & 0.500 \\
Single & $1,144,762$ & 0.478 & 0.500 \\
Couple & $1,144,762$ & 0.563 & 0.496 \\
No child & $1,144,762$ & 0.437 & 0.496 \\
1 child & $1,144,762$ & 0.580 & 0.494 \\
children & $1,144,762$ & 0.173 & 0.379 \\
children & $1,144,762$ & 0.138 & 0.345 \\
4 children & $1,144,762$ & 0.061 & 0.240 \\
5 children and more & $1,144,762$ & 0.024 & 0.153 \\
French & $1,144,762$ & 0.023 & 0.149 \\
European (other) & $1,144,762$ & 0.775 & 0.417 \\
North African & $1,144,762$ & 0.065 & 0.247 \\
Subsaharan African & $1,144,762$ & 0.080 & 0.272 \\
Other Nationality & $1,144,762$ & 0.046 & 0.210 \\
College diploma & $1,144,762$ & 0.033 & 0.178 \\
High School (final year and diploma) & $1,144,762$ & 0.217 & 0.412 \\
High school (excluding final year) and technical diploma & $1,144,762$ & 0.148 & 0.355 \\
Secondary school and no diploma & $1,144,762$ & 0.318 & 0.466 \\
Disabled & $1,144,762$ & 0.317 & 0.465 \\
\hline \hline & $1,144,762$ & 0.028 & 0.164 \\
\hline \hline
\end{tabular}


Table 3: Descriptive statistics of the sample at risk in the first semester of 2000

\begin{tabular}{lrrr}
\hline \hline Variable & N.Obs. & Mean & Std \\
\hline Exit types and unemployment spells & & & \\
Exit to job in the period & $1,026,093$ & 0.101 & 0.424 \\
Exit to non-employment in the period & $1,026,093$ & 0.058 & 0.361 \\
Unknown exit in the period & $1,026,093$ & 0.253 & 0.563 \\
Duration if exit to job in the period & 103,758 & 274.313 & 548.811 \\
Duration if exit to non-employment in the period & 59,776 & 327.977 & 689.502 \\
Duration if unknown exit in the period & 259,276 & 263.671 & 545.119 \\
Characteristics of unemployed workers & & & \\
Age & & & \\
Male & $1,026,093$ & 34.620 & 9.567 \\
Female & $1,026,093$ & 0.491 & 0.500 \\
Single & $1,026,093$ & 0.509 & 0.500 \\
Couple & $1,026,093$ & 0.562 & 0.496 \\
No child & $1,026,093$ & 0.438 & 0.496 \\
1 child & $1,026,093$ & 0.613 & 0.487 \\
2 children & $1,026,093$ & 0.155 & 0.362 \\
children & $1,026,093$ & 0.124 & 0.329 \\
4 children & $1,026,093$ & 0.063 & 0.243 \\
5 children and more & $1,026,093$ & 0.025 & 0.156 \\
French & $1,026,093$ & 0.020 & 0.141 \\
European (other) & $1,026,093$ & 0.731 & 0.444 \\
North African & $1,026,093$ & 0.064 & 0.245 \\
Subsaharan African & $1,026,093$ & 0.093 & 0.290 \\
Other Nationality & $1,026,093$ & 0.068 & 0.252 \\
College diploma & $1,026,093$ & 0.044 & 0.206 \\
High School (final year and diploma) & $1,026,093$ & 0.244 & 0.430 \\
High school (excluding final year) and technical diploma & $1,026,093$ & 0.173 & 0.379 \\
Secondary school and no diploma & $1,026,093$ & 0.290 & 0.454 \\
Disabled & $1,026,093$ & 0.293 & 0.455 \\
\hline \hline & $1,026,093$ & 0.045 & 0.208 \\
\hline \hline & & &
\end{tabular}


Table 4: Results of the first-stage estimation, semester 1 in years 1994 and 2000

\begin{tabular}{|c|c|c|}
\hline & 1st semester 1994 & 1st semester 2000 \\
\hline Age/100 & $\begin{array}{c}-4.153^{* * *} \\
(0.251)\end{array}$ & $\begin{array}{c}-1.670^{* * *} \\
(0.282)\end{array}$ \\
\hline (Age/100) squared & $\begin{array}{c}3.201^{* * *} * \\
(0.353)\end{array}$ & $\begin{array}{l}-0.282 \\
(0.390)\end{array}$ \\
\hline Male & $<$ ref $>$ & $<$ ref $>$ \\
\hline Female & $\begin{array}{c}-0.183^{* * *} \\
(0.005)\end{array}$ & $\begin{array}{c}-0.201^{* * *} \\
(0.006)\end{array}$ \\
\hline Single & $<\mathrm{ref}>$ & $<\mathrm{ref}>$ \\
\hline Couple & $\begin{array}{c}0.128^{* * *} \\
(0.007)\end{array}$ & $\begin{array}{c}0.107^{* * *} \\
(0.008)\end{array}$ \\
\hline No child & $<\mathrm{ref}>$ & $<\mathrm{ref}>$ \\
\hline 1 child & $\begin{array}{c}-0.111^{* * *} \\
(0.009)\end{array}$ & $\begin{array}{c}-0.085^{* * *} \\
(0.010)\end{array}$ \\
\hline 2 children & $\begin{array}{c}-0.096^{* * *} \\
(0.010)\end{array}$ & $\begin{array}{l}-0.003 \\
(0.011)\end{array}$ \\
\hline 3 children & $\begin{array}{c}-0.171^{* * *} \\
(0.014)\end{array}$ & $\begin{array}{c}-0.075^{* * *} \\
(0.016)\end{array}$ \\
\hline 4 children & $\begin{array}{c}-0.175^{* * *} \\
(0.023)\end{array}$ & $\begin{array}{c}-0.100^{* * *} \\
(0.026)\end{array}$ \\
\hline 5 children and more & $\begin{array}{c}-0.238^{* * *} \\
(0.027)\end{array}$ & $\begin{array}{c}-0.135^{* * *} \\
(0.033)\end{array}$ \\
\hline French & $<\mathrm{ref}>$ & $<\mathrm{ref}>$ \\
\hline European & $\begin{array}{l}-0.014 \\
(0.012)\end{array}$ & $\begin{array}{c}-0.058^{* * *} \\
(0.014)\end{array}$ \\
\hline North African & $\begin{array}{c}-0.402^{* * *} \\
(0.013)\end{array}$ & $\begin{array}{c}-0.383^{* * *} \\
(0.014)\end{array}$ \\
\hline Subsaharan African & $\begin{array}{c}-0.723^{* * *} \\
(0.019)\end{array}$ & $\begin{array}{c}-0.752^{* * *} \\
(0.019)\end{array}$ \\
\hline Other Nationality & $\begin{array}{c}-0.536^{* * *} \\
(0.021)\end{array}$ & $\begin{array}{c}-0.719^{* * * *} \\
(0.023)\end{array}$ \\
\hline College diploma & $<\mathrm{ref}>$ & $<$ ref $>$ \\
\hline High School (final year and diploma) & $\begin{array}{c}-0.234^{* * *} \\
(0.008)\end{array}$ & $\begin{array}{c}-0.292^{* * *} \\
(0.009)\end{array}$ \\
\hline High school (excluding final year) and technical diploma & $\begin{array}{c}-0.320^{* * *} \\
(0.007)\end{array}$ & $\begin{array}{c}-0.338^{* * *} \\
(0.008)\end{array}$ \\
\hline Secondary school and no diploma & $\begin{array}{c}-0.583^{* * *} \\
(0.009)\end{array}$ & $\begin{array}{c}-0.629^{* * *} \\
(0.010)\end{array}$ \\
\hline Not disabled & $<\mathrm{ref}>$ & $<\mathrm{ref}>$ \\
\hline Disabled & $\begin{array}{c}-0.371^{* * *} \\
(0.021) \\
\end{array}$ & $\begin{array}{c}-0.381^{* * *} \\
(0.019) \\
\end{array}$ \\
\hline Number of individuals at risk & 1144762 & 1026093 \\
\hline Number of exits within the interval & 144092 & 103758 \\
\hline Mean log-likelihood & -6.281 & -6.028 \\
\hline
\end{tabular}

Note: ${ }^{* *}$ : significant at $1 \%$ level; $* *$ : significant at $5 \%$ level; *: significant at $10 \%$ level. 
Table 5: Propensity score: the effect of municipality characteristics on the designation of an enterprise zone

\begin{tabular}{lccc}
\hline \hline & Weights & $\begin{array}{c}\text { Weights, inclusion of } \\
\text { past municipality effect }\end{array}$ & No weights \\
\hline Job density, 60' by private vehicle & $-3.999^{*}$ & -3.357 & $-4.171^{*}$ \\
Proportion of no diploma & $(2.109)$ & $(2.260)$ & $(2.298)$ \\
& $37.779^{*}$ & 33.447 & 24.029 \\
Proportion of technical diplomas & $(22.249)$ & $(23.998)$ & $(22.865)$ \\
& 20.998 & 5.860 & 0.974 \\
Proportion of college diplomas & $(28.215)$ & $(31.527)$ & $(28.900)$ \\
& 38.978 & 27.180 & 17.299 \\
Distance to the nearest EZ & $(29.889)$ & $(32.809)$ & $(31.336)$ \\
& -0.027 & -0.033 & $(0.024)$ \\
Proportion of individuals below 25 in 1990 & $(0.024)$ & $(0.025)$ & $11.834^{* *}$ \\
Population in 1990 & $17.125^{* * *}$ & $14.890^{* * *}$ & $(5.256)$ \\
& $(5.156)$ & $(5.320)$ & $0.019^{*}$ \\
Average net income in 96 & $0.021^{* *}$ & $0.022^{* *}$ & $(0.011)$ \\
& $(0.009)$ & $(0.009)$ & -2.033 \\
Past municipality effect in exit to job & $-4.975^{* * *}$ & $-5.140^{* * *}$ & $(1.593)$ \\
Constant & $(1.563)$ & $(1.636)$ & .477 \\
\hline Nb. observations & & $4.014^{*}$ & $(2.323)$ \\
Pseudo- $R^{2}$ & -32.115 & -1.447 & -16.526 \\
\hline \hline
\end{tabular}

Note: $* * *$ : significant at $1 \%$ level; **: significant at $5 \%$ level; *: significant at $10 \%$ level.

The sample is restricted to municipalities with a population between 8,000 and 100,000 in 1990. The first and second columns are weighted by the square root of the number of unemployed workers at risk at the beginning of period 8 , and the third column is not weighted. Past municipality effect refers to the average of municipality effects in previous semesters, as estimated in the 1st stage (SPLE).

We also used alternative specifications including in the set of explanatory variables, for instance: the job density within a 60' radius by public transport, the unemployment rate in 1990, the proportions of Europeans (French excluded), North Africans, Subsaharan Africans and other nationalities. The estimated coefficients were not significant and a Chi-square test did not reject the absence of joint significance. Consequently, we dropped these variables from the specification.

Table 6: Descriptive statistics on the propensity score in treated and control groups

\begin{tabular}{lccccc}
\hline \hline Group & Nb. obs. & Mean & Std. Dev. & Min & Max \\
\hline Non-treated & 258 & .034 & .093 & 0 & .643 \\
Non-treated, propensity score $>.0005$ & 135 & .065 & .121 & 0 & .643 \\
Treated & 13 & .497 & .352 & .001 & .995 \\
\hline \hline
\end{tabular}

Note: The observation unit is a municipality between 8,000 and 100,000 inhabitants. The propensity score was computed from the results of Table 5, column (1). 
Table 7: The effect of designation and treatment on semester-specific municipality effects (OLS)

\begin{tabular}{|c|c|c|c|c|}
\hline & $\begin{array}{c}\text { No control } \\
\text { support : } z>z \text { min }\end{array}$ & $\begin{array}{c}\text { Propensity score } \\
\text { support : } z>z \text { min }\end{array}$ & $\begin{array}{c}\text { Propensity score } \\
\text { support : } z>z m i n \\
\text { Score in splines }\end{array}$ & $\begin{array}{c}\text { Propensity score } \\
\text { support : } z>z 10\end{array}$ \\
\hline Municipality & $-.035^{* *}$ & $.074^{* * *}$ & $.043^{* *}$ & $.070^{* * *}$ \\
\hline designated for an EZ & $(.017)$ & $(.019)$ & $(.017)$ & $(.020)$ \\
\hline EZ treatment effect & -.024 & -.023 & -.021 & -.030 \\
\hline Propensity score & & $\begin{array}{c}. .229^{* * *} \\
(.018)\end{array}$ & & $\begin{array}{c}-.154^{* * *} \\
(.020)\end{array}$ \\
\hline P. score, spline 1 & & & $\begin{array}{c}-3.42^{* * *} \\
(.41)\end{array}$ & \\
\hline P. score, spline 2 & & & $\begin{array}{c}-.394^{* * *} \\
(.131)\end{array}$ & \\
\hline P. score, spline 3 & & & $\begin{array}{l}.863^{* * *} \\
(.132)\end{array}$ & \\
\hline P. score, spline 4 & & & $\begin{array}{c}-1.008^{* * *} \\
(.114)\end{array}$ & \\
\hline P. score, spline 5 & & & $\begin{array}{l}-.099 \\
(.069)\end{array}$ & \\
\hline Nb observations & 2960 & 2960 & 2960 & 2960 \\
\hline$R^{2}$ & .510 & .534 & .571 & .512 \\
\hline
\end{tabular}

Note: ${ }^{* *}$ : significant at $1 \%$ level; $* *$ : significant at $5 \%$ level; *: significant at $10 \%$ level.

Weight: number of unemployed workers at risk. Year dummies are included and are not reported here. The standard errors are computed using the sandwich formula and the generated regressor issue due to the estimated propensity score is not corrected. zmin: minimum of the score for the treated municipalities divided by two. $z 10$ : first decile of the score for treated municipalities. Value of the bounds for splines determined so that treated municipalities are allocated equally in categories. 
Table 8: The effect of designation and treatment on semester-specific municipality effects: Matching, within and first-difference

\begin{tabular}{lccc}
\hline \hline & Matching & Within estimator & First-difference \\
\hline Municipality & $.074^{* * *}$ & & \\
designated for an EZ & $(.019)$ & & \\
EZ treatment effect & -.023 & $-.024^{*}$ & $.049^{* * *}$ \\
& $(.021)$ & $(.012)$ & $(.019)$ \\
Propensity score & $-.229^{* * *}$ & & \\
& $(.018)$ & & $n u_{t-1}+n u_{t}$ \\
\hline Weight & $n u_{t}$ & $n u_{t}$ & 2812 \\
Nb observations & 2960 & 2960 & \\
\hline \hline
\end{tabular}

Note: $* * *$ : significant at $1 \%$ level; $* *$ : significant at $5 \%$ level; $*$ : significant at $10 \%$ level.

Standard errors are robust to heteroskedasticity. $n u_{t}$ : number of unemployed workers at risk at period t. Year dummies are included and are not reported here. 
Table 9: The effect of designation and treatment on semester-specific municipality effects treatment effect varying with time

\begin{tabular}{lccc}
\hline \hline & Matching & Within estimator & First-difference \\
\hline Municipality & $0.074^{* * *}$ & & \\
designated for an EZ & $(0.019)$ & & \\
Propensity score & $-0.229^{* * *}$ & & -0.009 \\
& $(0.018)$ & & $(0.006)$ \\
Treatment effect, & 0.010 & 0.011 & $0.043^{* *}$ \\
semester 8 & $(0.046)$ & $(0.022)$ & $(0.022)$ \\
Treatment effect, & -0.006 & -0.005 & 0.039 \\
semester 9 & $(0.043)$ & $(0.022)$ & $(0.026)$ \\
Treatment effect, & 0.025 & 0.022 & $0.059^{*}$ \\
semester 10 & $(0.052)$ & $(0.028)$ & $(0.031)$ \\
Treatment effect, & -0.016 & -0.020 & 0.027 \\
semester 11 & $(0.043)$ & $(0.019)$ & $(0.036)$ \\
Treatment effect, & -0.011 & -0.015 & 0.030 \\
semester 12 & $(0.054)$ & $(0.026)$ & $(0.040)$ \\
Treatment effect, & -0.026 & -0.029 & 0.025 \\
semester 13 & $(0.055)$ & $(0.025)$ & $(0.044)$ \\
Treatment effect, & 0.011 & 0.007 & 0.054 \\
semester 14 & $(0.055)$ & $(0.021)$ & $(0.048)$ \\
Treatment effect, & -0.062 & $-0.063^{* *}$ & -0.015 \\
semester 15 & $(0.060)$ & $(0.028)$ & $(0.052)$ \\
Treatment effect, & -0.023 & -0.027 & 0.024 \\
semester 16 & $(0.053)$ & $(0.031)$ & $(0.056)$ \\
Treatment effect, & -0.060 & $-0.062^{* *}$ & 0.005 \\
semester 17 & $(0.052)$ & $(0.028)$ & $(0.060)$ \\
Treatment effect, & -0.032 & -0.033 & 0.053 \\
semester 18 & $(0.054)$ & $(0.026)$ & $(0.064)$ \\
Treatment effect, & -0.045 & -0.044 & 0.038 \\
semester 19 & $(0.049)$ & $(0.033)$ & $(0.068)$ \\
Treatment effect, & -0.069 & $-0.067^{*}$ & 0.019 \\
semester 20 & $(0.057)$ & $(0.035)$ & $(0.071)$ \\
Constant & $-6.861^{* * *}$ & $-0.016^{* *}$ & $-0.125^{* * *}$ \\
& $(0.019)$ & $(0.007)$ & $(0.009)$ \\
\hline Weight & $n u_{t}$ & $n u_{t}$ & $n u_{t-1}+n u_{t}$ \\
Nb observations & 2960 & 2960 & 2812 \\
$R^{2}$ & .535 & & \\
\hline \hline & & & \\
\hline
\end{tabular}

Note: ***: significant at $1 \%$ level; **: significant at $5 \%$ level; *: significant at $10 \%$ level.

$n u_{t}$ : number of unemployed workers at risk at period t. Year dummies are included and are not reported here. Standard errors are robust to heteroskedasticity. 
Table 10: The effect of designation and treatment on semester-specific municipality effects robustness to changes of semesters,

specific effect for EZ with a small proportion of the population in the municipality

\begin{tabular}{lccccc}
\hline \hline & Periods: & Periods: & Period: & Period: & Specific effect for \\
& less than 13 & 5 to 9 & 8 & 8 & small-proportion EZ \\
\hline EZ treatment effect & $.031^{* *}$ & $.042^{* *}$ & .035 & $.058^{* * *}$ & $.057^{* * *}$ \\
& $(.014)$ & $(.019)$ & $(.025)$ & $(.019)$ & $(.016)$ \\
EZ treatment effect & & & & & $-.041^{* *}$ \\
X small-proportion EZ & & & & & $(.018)$ \\
Propensity score & $-.008^{*}$ & $-.021^{*}$ & .049 & & $-.007^{*}$ \\
& $(.004)$ & $(.012)$ & $(.039)$ & & $(.004)$ \\
\hline Nb observations & 1628 & 592 & 148 & 148 & 1628 \\
\hline \hline
\end{tabular}

Note: $* * *$ : significant at $1 \%$ level; **: significant at $5 \%$ level; *: significant at $10 \%$ level.

Year dummies are included and are not reported here. Small-proportion EZ are the EZ whose population accounts for less than $50 \%$ of the population of the municipalities where the EZ is located. Estimation method: FGLS with a constant within-municipality unrestricted covariance matrix. 


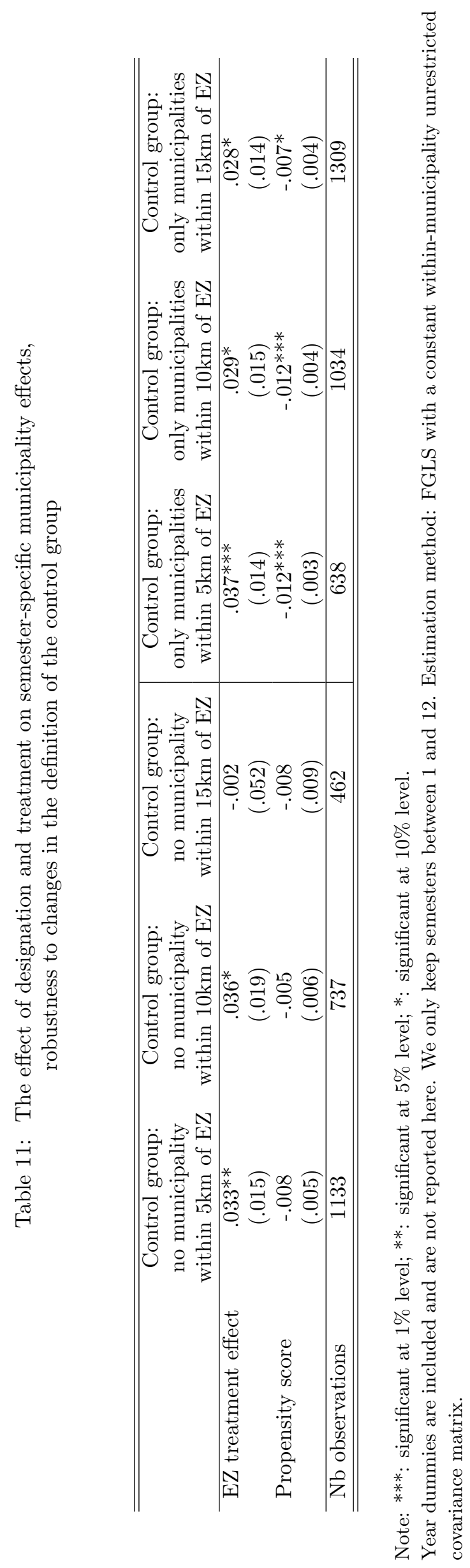


Table 12: The effect of designation and treatment on semester-specific municipality effects, robustness to changes in the specification of the treatment group

\begin{tabular}{lccc}
\hline \hline & $\begin{array}{c}\text { Treatment group: } \\
\text { municipalities with } \\
\text { an EZ }\end{array}$ & $\begin{array}{c}\text { Treatment group: } \\
\text { municipalities less } \\
\text { than 2km of an EZ }\end{array}$ & $\begin{array}{c}\text { Treatment group: } \\
\text { municipalities less } \\
\text { than 3km of an EZ }\end{array}$ \\
\hline EZ treatment effect & $.031^{* *}$ & .010 & .009 \\
Propensity score & $(.014)$ & $(.012)$ & $(.010)$ \\
& $-.008^{*}$ & -.003 & -.001 \\
\hline Nb observations & $(.004)$ & $(004)$ & $1.004)$ \\
\hline \hline
\end{tabular}

Note: $* * *$ : significant at $1 \%$ level; $* *$ : significant at $5 \%$ level; $*$ : significant at $10 \%$ level.

Year dummies are included and are not reported here. We only keep semesters between 1 and 12. Estimation method: FGLS with a constant within-municipality unrestricted covariance matrix. "Municipalities with an EZ" corresponds to our baseline treatment group and includes 13 municipalities. There are 24 municipalities within $2 \mathrm{~km}$ of an EZ and 51 municipalities within $3 \mathrm{~km}$ of an EZ. 
Table 13: The effect of designation and treatment on semester-specific municipality effects, robustness to changes in the specification of the propensity score and weighting scheme

\begin{tabular}{lccc}
\hline \hline & $\begin{array}{c}\text { Propensity score: } \\
\text { inclusion of average } \\
\text { of past municipality } \\
\text { effects }\end{array}$ & $\begin{array}{c}\text { Weighting: } \\
\text { inverse of the } \\
\text { 1st stage } \\
\text { standard errors }\end{array}$ & $\begin{array}{c}\text { Weighting: } \\
\text { no weights }\end{array}$ \\
\hline EZ treatment effect & $.032^{* *}$ & $.029^{* *}$ & $.042^{* * *}$ \\
& $(.014)$ & $(.014)$ & $(.016)$ \\
Propensity score & $-.008^{* *}$ & -.048 & $-.013^{* * *}$ \\
& $(.004)$ & $(.030)$ & $(.005)$ \\
\hline Nb observations & 1518 & 1617 & 1276 \\
\hline \hline
\end{tabular}

Note: ${ }^{* *}$ : significant at $1 \%$ level; $* *$ : significant at $5 \%$ level; $*$ : significant at $10 \%$ level.

Year dummies are included and are not reported here. We only keep semesters between 1 and 12. Estimation method: FGLS with a constant within-municipality unrestricted covariance matrix. The results of the propensity score equation when including the average of past municipality effects is given in Table 1, column 2 . 
Table 14: The effect of treatment on semester-specific municipality effects, robustness to the inclusion of the present and past log-entry rates, and the inclusion of a lagged treatment effect

\begin{tabular}{lccc}
\hline \hline & $\begin{array}{c}\text { Inclusion of the } \\
\text { log-entry rate in t }\end{array}$ & $\begin{array}{c}\text { Inclusion of the } \\
\text { log-entry rate in t-1 }\end{array}$ & $\begin{array}{c}\text { Inclusion of a } \\
\text { lagged treatment effect }\end{array}$ \\
\hline EZ treatment effect & $.030^{* *}$ & $.034^{* * *}$ & $.036^{* *}$ \\
Lagged treatment effect & $(.013)$ & $(.015)$ & $(.014)$ \\
Log-entry rate & & & -.012 \\
& & $.015)$ \\
Propensity score & $.111^{* * *}$ & -.051 & \\
& $(.027)$ & $(.032)$ & $-.008^{*}$ \\
\hline Nb observations & $-.008^{*}$ & $-.011^{* *}$ & $(.004)$ \\
\hline \hline
\end{tabular}

Note: $* * *$ : significant at $1 \%$ level; **: significant at $5 \%$ level; *: significant at $10 \%$ level.

Year dummies are included and are not reported here. We only keep semesters between 1 and 12. Estimation method: FGLS with a constant within-municipality unrestricted covariance matrix. The entry rate is defined as the ratio between the number of entries during the semester and the number of unemployed workers at risk at the beginning of the semester. 
Table 15: The effect of treatment on the logarithm of entry and exit rates

\begin{tabular}{lcccc}
\hline \hline & $\begin{array}{c}\text { Entry rate } \\
\text { into unemployment }\end{array}$ & $\begin{array}{c}\text { Exit rate } \\
\text { to job }\end{array}$ & $\begin{array}{c}\text { Exit rate } \\
\text { to non-employment }\end{array}$ & $\begin{array}{c}\text { Exit rate } \\
\text { to unknown }\end{array}$ \\
\hline EZ treatment effect & .011 & $.040^{* * *}$ & .039 & .013 \\
& $(.021)$ & $(.015)$ & $(.024)$ & $(.014)$ \\
Propensity score & $-.077^{* * *}$ & $-.009^{* * *}$ & $-.007^{*}$ & .001 \\
& $(.018)$ & $(.003)$ & $(.004)$ & $(.004)$ \\
\hline Nb observations & 1628 & 1628 & 1628 & 1628 \\
\hline \hline
\end{tabular}

Note: ${ }^{* *}$ : significant at $1 \%$ level; ${ }^{* *}$ : significant at $5 \%$ level; $*$ : significant at $10 \%$ level.

Year dummies are included and are not reported here. We only keep semesters between 1 and 12. Estimation method: FGLS with a constant within-municipality unrestricted covariance matrix. The entry (resp. exit) rate is defined as the ratio between the number of entries (resp. exits) during the semester and the number of unemployed workers at risk at the beginning of the semester. 
Figure 1: Unemployment rate, entry rate into unemployment and exit rate from unemployment (2nd semester of 1993 - 1st semester of 2003)

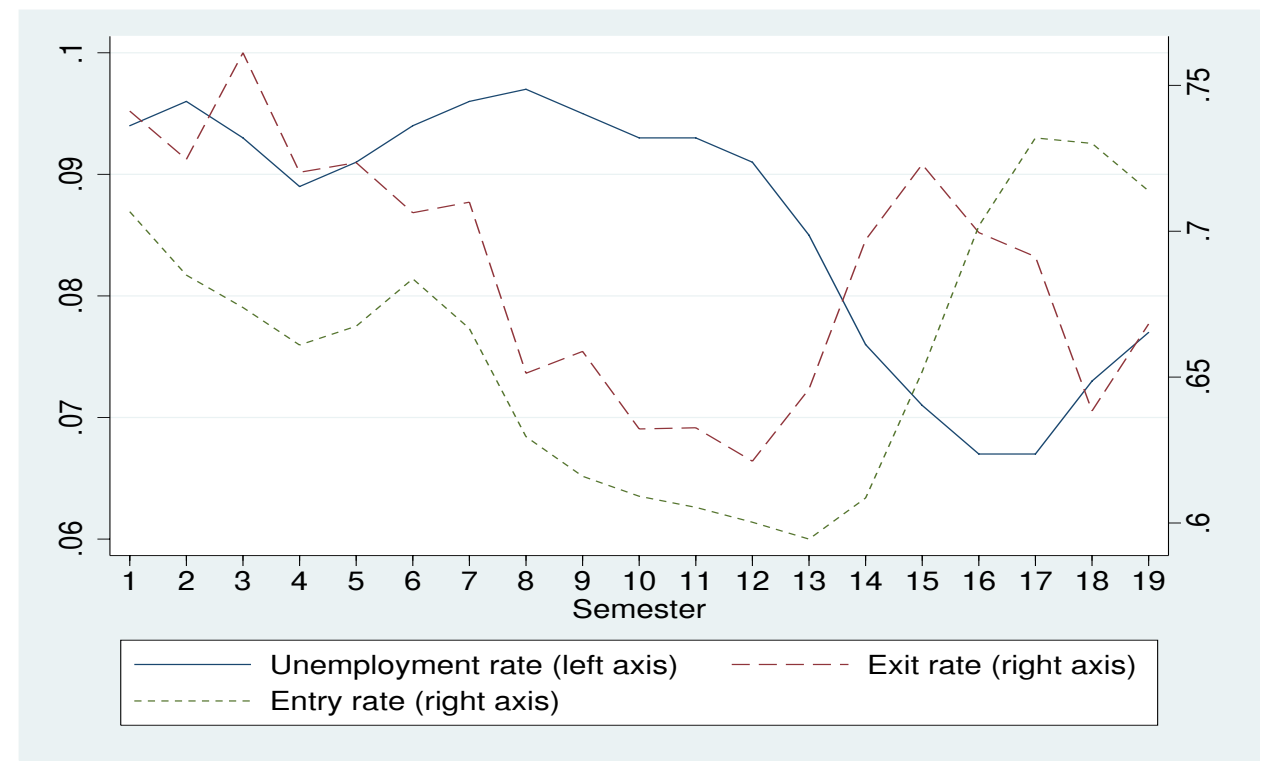

Note: Semester 1 refers to the second semester of 1993. For the entry rate, we represent the average of the current semester and the following semester to smooth the curve and avoid seasonality effects.

Figure 2: Exit rate to job, non-employment and for unknown reasons

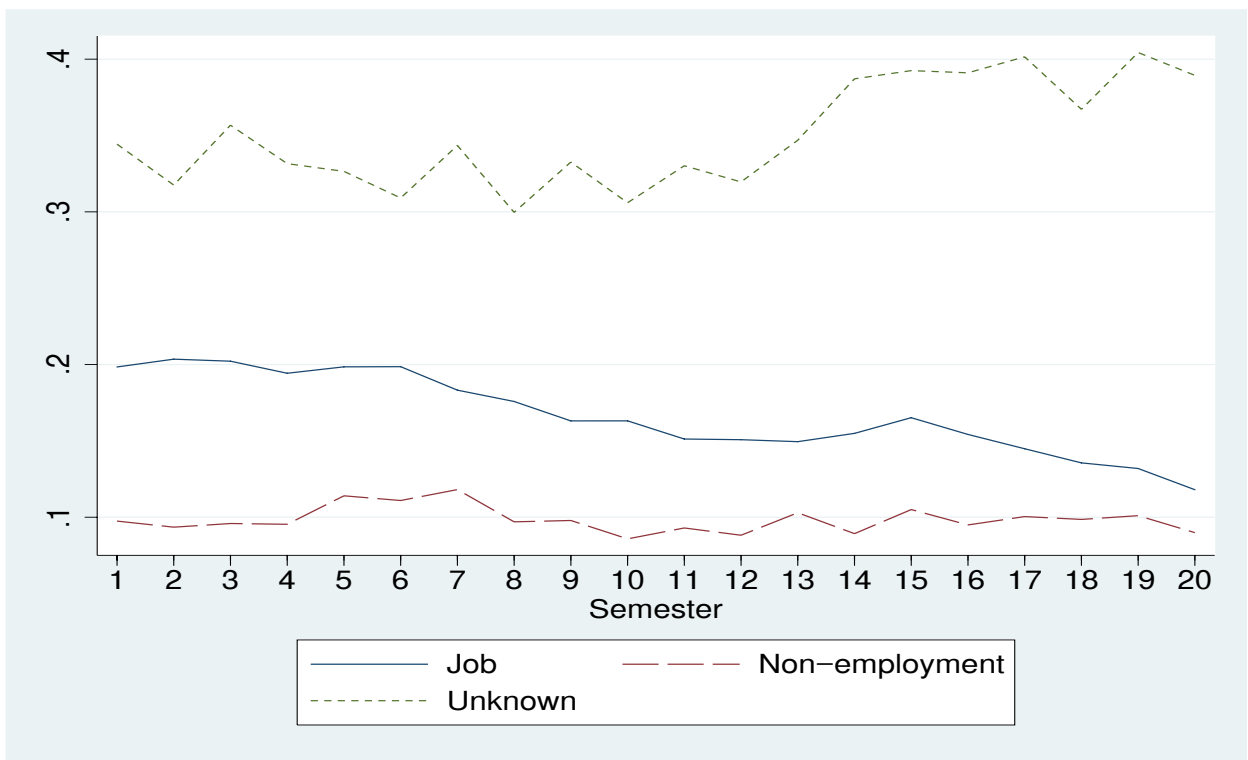

Note: Semester 1 refers to the second semester of 1993. 
Figure 3: Exit rates to job, by group of municipalities

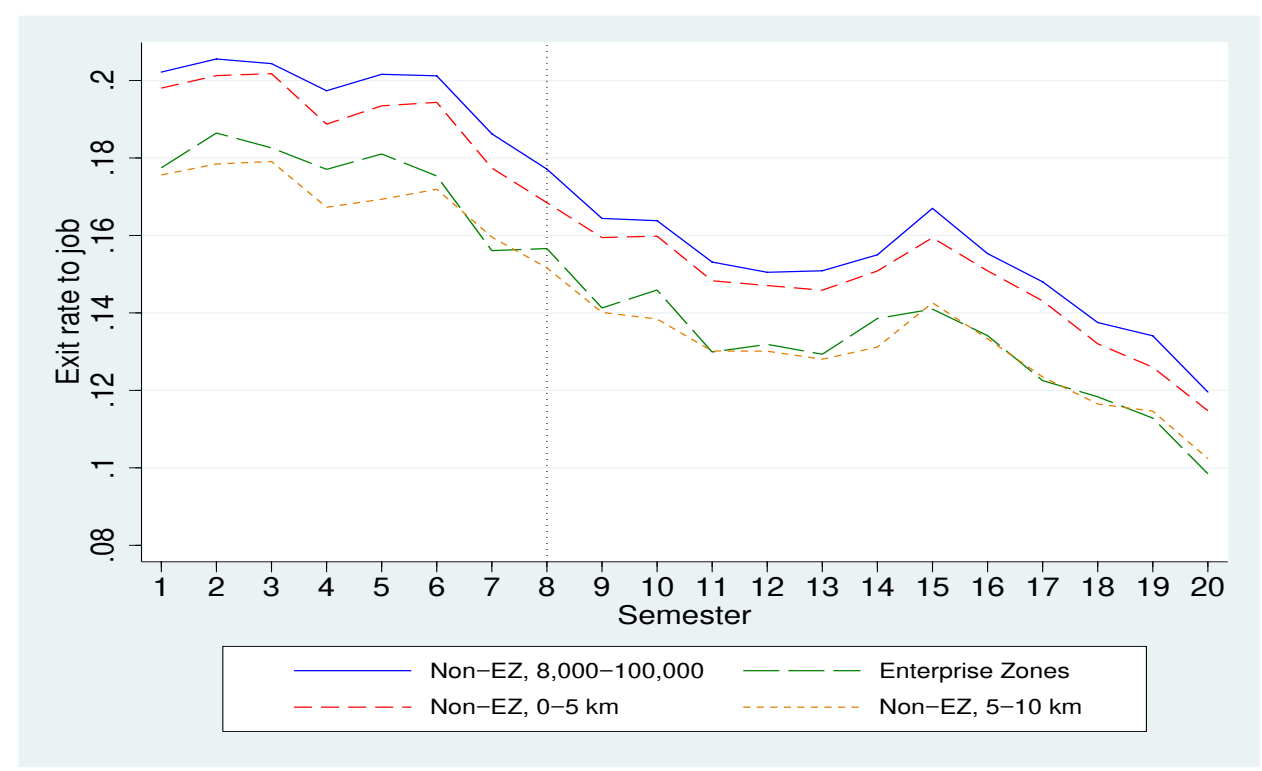

Note: Semester 1 refers to the second semester of 1993. Non-EZ: municipalities which do not include an EZ. 8,000-100,000: population between 8,000 and 100,000 in 1990. 0-Xkm: between 0 and Xkm of a municipality including an EZ. Enterprise zones: municipalities which include an EZ.

Figure 4: Exit rates to non-employment, by group of municipalities

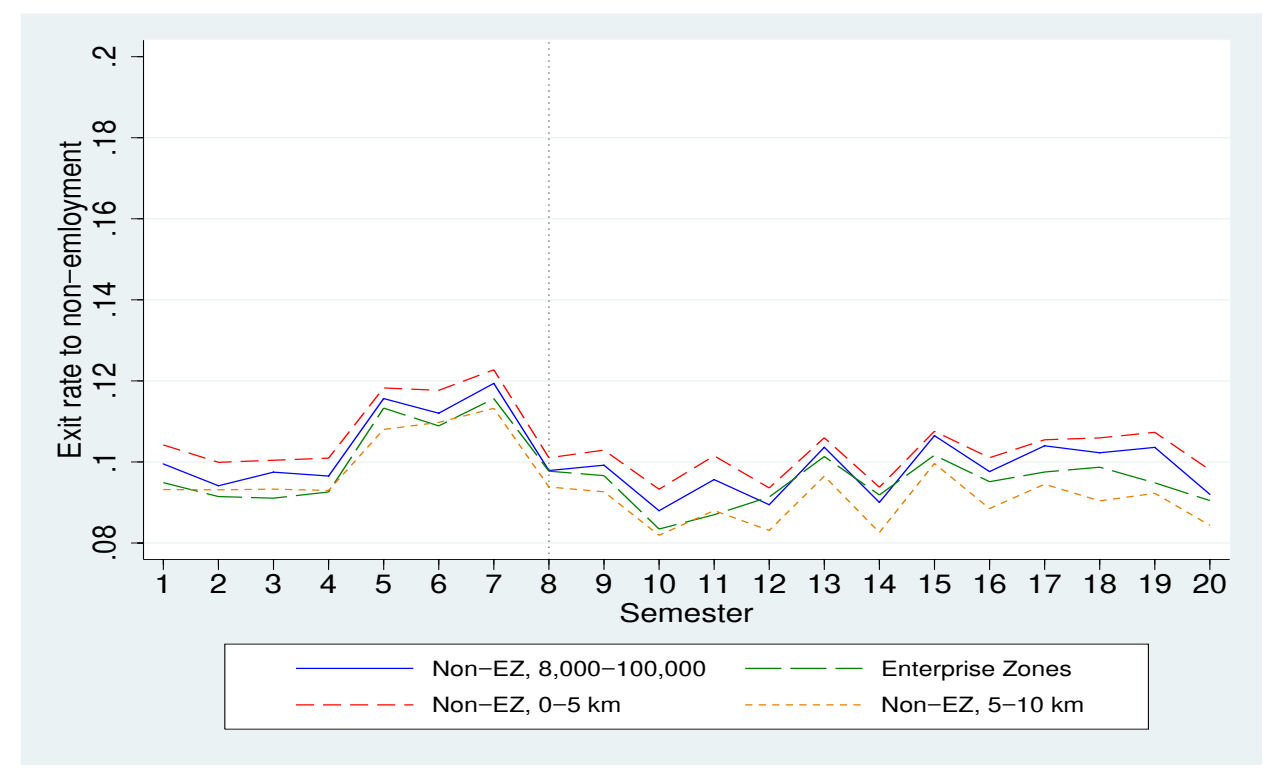

Note: Semester 1 refers to the second semester of 1993. Non-EZ: municipalities which do not include an EZ. 8,000-100,000: population between 8,000 and 100,000 in 1990. 0 -Xkm: between 0 and Xkm of a municipality including an EZ. Enterprise zones: municipalities which include an EZ. 
Figure 5: Rates of exit for unknown reason, by group of municipalities

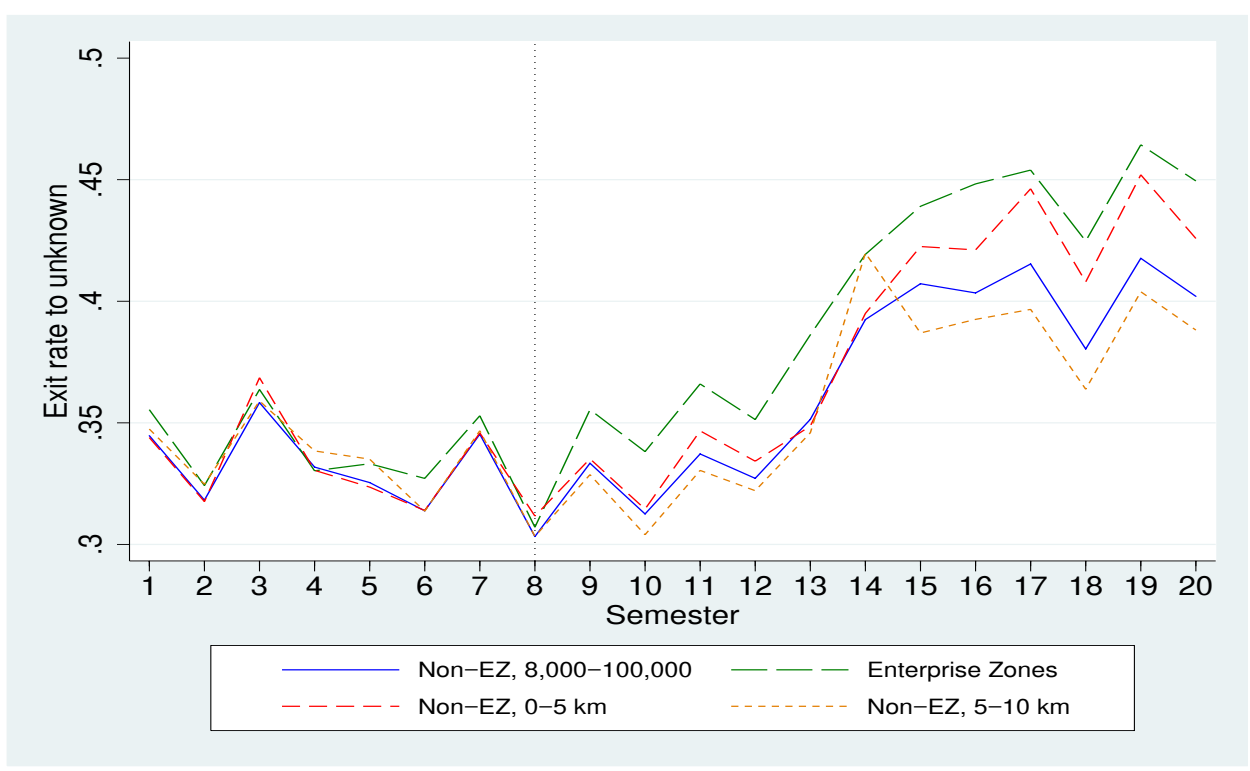

Note: Semester 1 refers to the second semester of 1993. Non-EZ: municipalities which do not include an EZ. 8,000-100,000: population between 8,000 and 100,000 in 1990. 0 -Xkm: between 0 and Xkm of a municipality including an EZ. Enterprise zones: municipalities which include an EZ.

Figure 6: Exit rate to job, by proportion of EZ population within the municipality

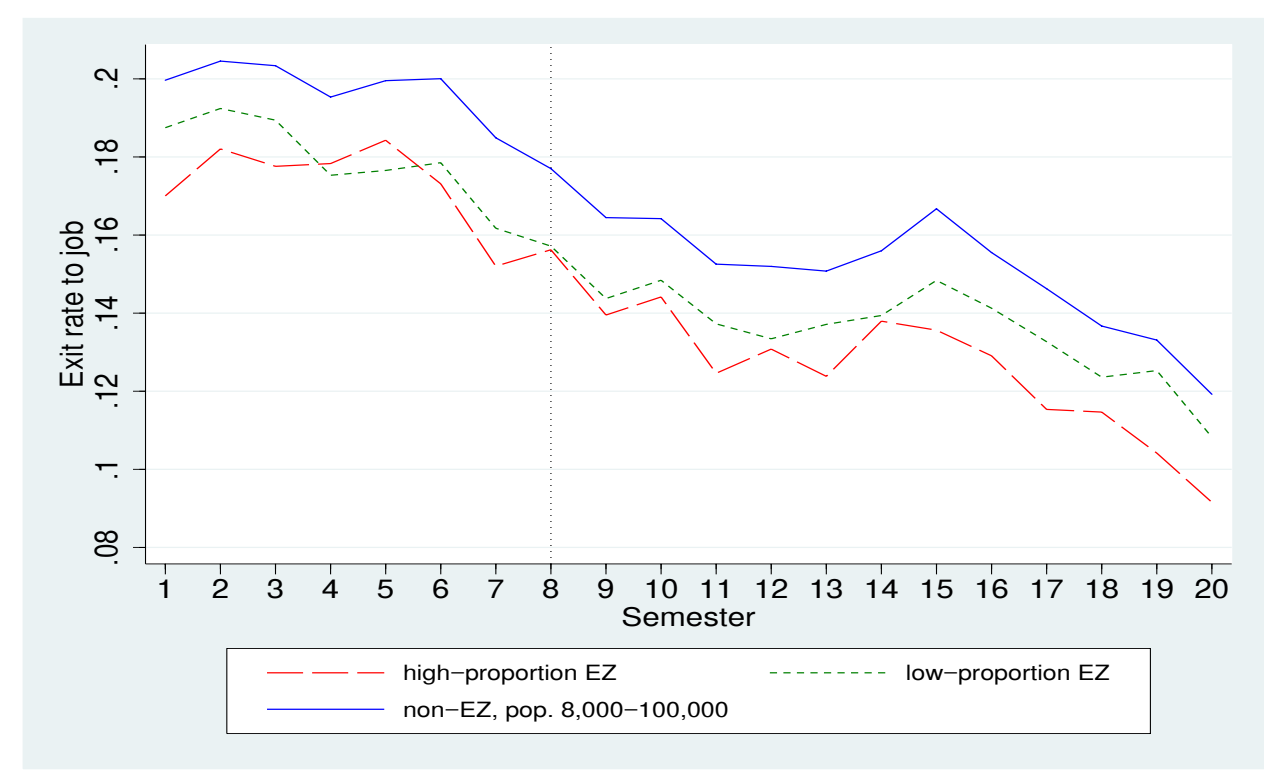

Note: Semester 1 refers to the second semester of 1993. High-proportion EZ (resp. low-proportion EZ): municipalities including an EZ which accounts for more (resp. less) than 50\% of the population of those municipalities in 1990. Non-EZ: municipalities which do not include an EZ. 8,000-100,000: population between 8,000 and 100,000 in 1990 . 
Figure 7: Semester-specific risk sets

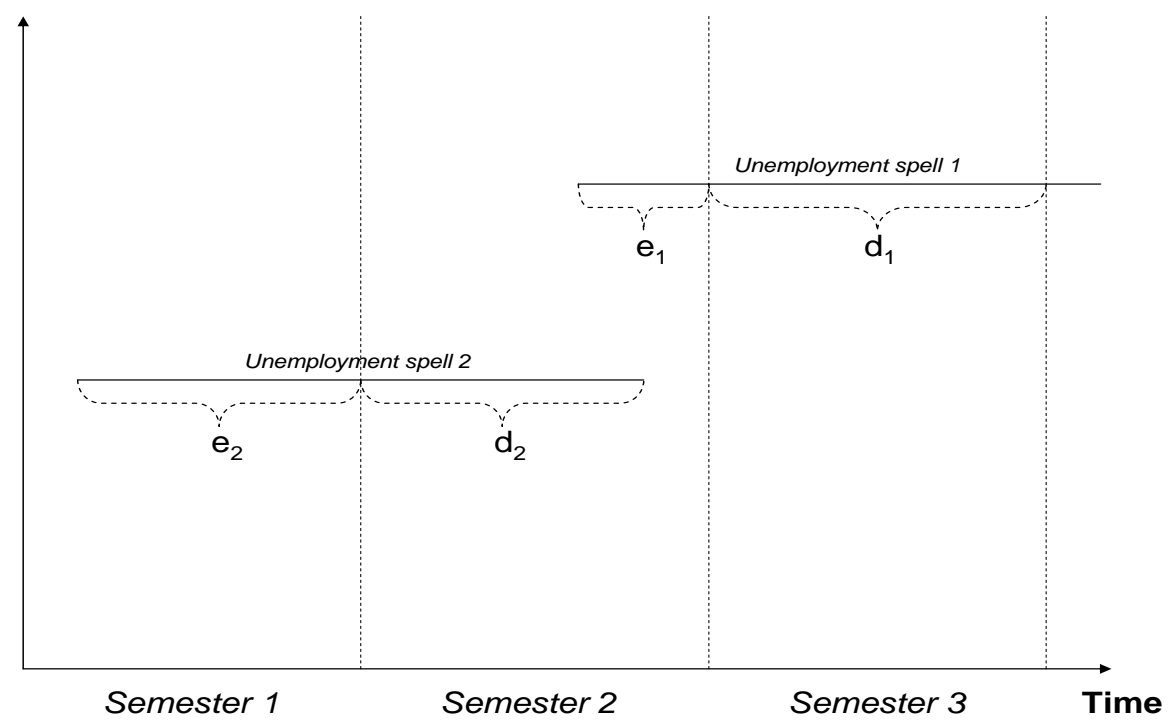

